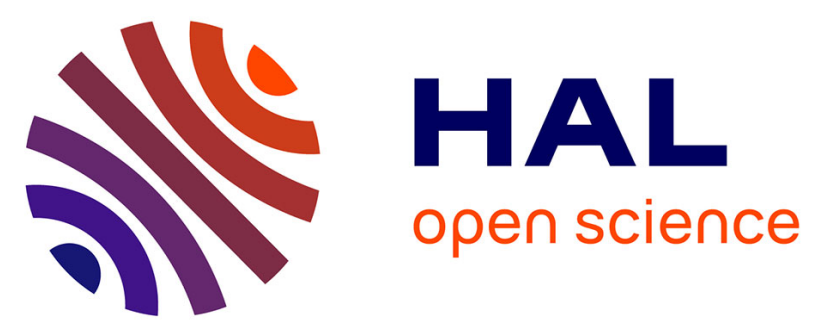

\title{
Finite difference simulations of seismic wave propagation for the 2007 Mw 6.6 Niigata-ken Chuetsu-Oki earthquake: Validity of models and reliable input ground motion in the near field
}

Hideo Aochi, Ariane Ducellier, Fabrice Dupros, Mickael Delatre, Thomas

Ulrich, Florent de Martin, Masayuki Yoshimi

\section{To cite this version:}

Hideo Aochi, Ariane Ducellier, Fabrice Dupros, Mickael Delatre, Thomas Ulrich, et al.. Finite difference simulations of seismic wave propagation for the $2007 \mathrm{Mw} 6.6$ Niigata-ken Chuetsu-Oki earthquake: Validity of models and reliable input ground motion in the near field. Pure and Applied Geophysics, 2013, 170 (1-2), pp.43-64. 10.1007/s00024-011-0429-5 . hal-00980238

\section{HAL Id: hal-00980238 \\ https: / hal-brgm.archives-ouvertes.fr/hal-00980238}

Submitted on 17 Apr 2014

HAL is a multi-disciplinary open access archive for the deposit and dissemination of scientific research documents, whether they are published or not. The documents may come from teaching and research institutions in France or abroad, or from public or private research centers.
L'archive ouverte pluridisciplinaire HAL, est destinée au dépôt et à la diffusion de documents scientifiques de niveau recherche, publiés ou non, émanant des établissements d'enseignement et de recherche français ou étrangers, des laboratoires publics ou privés. 
1 Submitted to special issue of PAGEOPH (Jan 2011), revision on July 2011, accepted on Sept 22011.

3

4 Finite difference simulations of seismic wave propagation for the

52007 Mw 6.6 Niigata-ken Chuetsu-Oki earthquake: Validity of

6 models and reliable input ground motion in the near field.

7

8 Hideo Aochi ${ }^{1}$, Ariane Ducellier ${ }^{1}$, Fabrice Dupros $^{2}$, Mickael Delatre ${ }^{1}$, Thomas Ulrich ${ }^{1}$, Florent

9 de Martin $^{1}$, and Masayuki Yoshimi ${ }^{3,1}$

10

$11{ }^{1}$ Natural Risks and $\mathrm{CO}_{2}$ Storage Safety Division, Bureau de Recherches Géologiques et

12 Minières, Orléans, France

$13{ }^{2}$ Digital Information Services, Bureau de Recherches Géologiques et Minières, Orléans,

14 France

$15{ }^{3}$ Geological Survey of Japan, National Institute of Advanced Industrial Science and

16 Technology, Tsukuba, Japan

17

18 


\section{Abstract}

20 Finite difference simulations of seismic wave propagation are performed in the Niigata area,

21 Japan, for the $2007 \mathrm{Mw}$ 6.6 Niigata-ken Chuetsu-Oki earthquake at low frequencies. We test

22 three 3D structural models built independently in various studies. First aftershock simulations

23 are carried out. The model based on 3D tomography yields correct body waves in the near

24 field, but later phases are imperfectly reproduced due to the lack of shallow sediment layers;

25 other models based on various 1D/2D profiles and geological interpretation provide good site

26 responses but generate seismic phases that may be shifted from those actually observed. Next,

27 for the mainshock simulations, we adopt two different finite source models that differ in the

28 near-field ground motion, especially above the fault plane (but under the sea) and then along

29 the coastline. Each model is found to be calibrated differently for the given stations. For

30 engineering purposes, the variations observed in simulated ground motion are significant, but

31 for seismological purposes, additional parameter calibrations would be possible for such a

32 complex 3D case.

33

34 


\section{Introduction}

The 2007 Mw 6.6 Niigata-ken Chuetsu-oki earthquake occurred on 16 July slightly off of the northwest coastline of the Japanese mainland (Figure 1). The hypocentral depth is about $10 \mathrm{~km}$ and the fault mechanism is reverse, causing no significant surface rupture. Although modern structures incurred little significant damage, the event did shut down the Kashiwazaki-Kariwa nuclear power plant located above the inferred fault plane, which induced changes in the seismic hazard evaluation criteria applied to nuclear power plants. This earthquake's mechanism is quite complex and remains uncertain despite the dense observation network in operation (cf. Aoi et al., 2008). The main reason for this is that the subsurface structure is so complex that commonly used algorithms based on a 1D structure model are unable to accurately determine aftershock locations (Kato et al., 2008, 2009; Shinohara et al., 2008). Immediately after the mainshock, high acceleration levels measured on seismic records along the coast tended to indicate that the fault orientation was northwest dipping, despite the fact that the geological structure would indicate a southeast dipping fault. However on the basis of aftershock observations obtained from arrays deployed for one month after the mainshock, the interpretation that predominantly emerges is that the major part of faulting is southeast dipping (Kato et al., 2009). Multisegment models are inferred from the InSAR observations (Aoki et al., 2008; Nishimura et al., 2008), and the possibility of rupture transfer between multisegment models is also dynamically simulated (Aochi \& Kato, 2010). Thus understanding this earthquake is a seismologically challenging problem, and it is worth ascertaining how well we can reproduce the ground motion using the known seismological information for this earthquake.

The basic concept behind the seismic hazard evaluation is to be able to predict ground motion under a given situation (cf. Douglas \& Aochi, 2008). As the time series analyses are increasingly called on in studying nonlinear soil-structure interaction in engineering 
seismology, the need is ever greater to provide the (input) ground motion quantitatively from seismological observations. Recent progress in numerical simulation and computational resources enables us to theoretically simulate ground motions at high frequencies up to several $\mathrm{Hz}$ by taking into account a complex source description and heterogeneous material parameters. However the frequency limit still stands at around $0.5-1 \mathrm{~Hz}$ when comparing with the observed data. Well-known, successful examples can be cited for the 1995 Hyogoken Nanbu (Kobe), Japan, earthquake or the 2004 Parkfield, California, earthquake (cf. Pitarka et al., 1998; Sasetyan, 2007). Both examples feature very shallow strike-slip faulting, relatively better studied than the fault mechanism for the 2007 Chuetsu-Oki earthquake we are dealing with in this paper. In any case, we believe it important to demonstrate how seismological insights serve to reproduce the ground motions in such difficult and complex cases.

In this paper, to study the validity of 3D subsurface structure models, we begin with simulations of the aftershocks, considered as point sources. We thence move on to the mainshock simulation using different finite source models provided by some seismological inversion studies. We compare the simulated ground motions with the records obtained on the permanent networks in terms of the waveforms and response spectra. In this paper, our aim is not to tune up the parameters to obtain the best model, but rather to analyze each model in detail and discuss how we can procure reliable input ground motion in the near field.

\section{Numerical Simulation Methodology}

All the simulations in this paper are carried out using the finite difference method based on the staggered grid with $4^{\text {th }}$ order in space and $2^{\text {nd }}$ order in time (Aochi $\&$ Madariaga, 2003, Dupros et al., 2008, references therein). The finite fault is approximated by a series of point sources in space (Olsen, 1994; Graves, 1996) and an arbitrary source time function can 
be considered at each point. How material heterogeneity dealt with is considered a crucial issue in the finite difference scheme (cf. Moczo et al., 2002; 2007). In this study, we follow Graves (1996) by averaging the material parameters, since the material interface is not always precisely defined at the FD grids we used.

We define our physical model volume as $110 \mathrm{~km}(\mathrm{EW})$ x $120 \mathrm{~km}(\mathrm{NS})$ x $30 \mathrm{~km}$ (depth). We use a grid spacing of $\Delta \mathrm{s}=200 \mathrm{~m}$ and a time step of $\Delta \mathrm{t}=0.01 \mathrm{sec}$ for most of the simulations; in some cases, we calculate with $\Delta \mathrm{s}=100 \mathrm{~m}$ and $\Delta \mathrm{t}=0.005 \mathrm{sec}$, and $\Delta \mathrm{s}=75 \mathrm{~m}$ and $\Delta \mathrm{t}=0.0035 \mathrm{sec}$ are used to check the convergence of simulations. For all cases, ten finite difference grids are added at each edge as a Perfectly Matched Layer absorbing boundary (Collino \& Tsogka, 2001; Komatitsch \& Martin, 2007). Thus, the numerical dimension is 570 x $620 \times 160=56$ million grids for $\Delta s=200 \mathrm{~m}, 1120 \times 1220 \times 310=423$ million for $\Delta s=100$ $\mathrm{m}$ and $1356 \times 1716 \times 429=1$ billion for $\Delta \mathrm{s}=75 \mathrm{~m}$. The calculation duration is 60 seconds. The upper frequency limit in the simulations is usually estimated as $f_{\max }=V_{\min } /(5 \Delta s)$, where $V_{\min }$ denotes the minimum wave velocity in the structural model being used (Levander, 1988). Based on several tests using different grid spacings and filter frequency ranges, we find it empirically to be a quite useful parameter.

Our simulation procedure is illustrated schematically in Figure 2. The input files both for the structure and the source need to be handled with care. For the structure, we read the original files provided by different studies and assign the material property at each grid in our simulation program. For the source models, however, we format the source files prior to the simulations after carefully ascertaining how the inversions have been achieved. Since the synthetic near-field ground motion is quite sensitive to the source description in time and space, in order to reproduce the ground motions using the source models inverted from the observations, we must understand exactly how they are solved in terms of the Green's function being used and detailed source time description (cf. Aochi et al., 2011). 
112 of wave propagation using finite difference methods (cf. Olsen et al., 2009; Furumura \& Saito,

113 2009). In order to be able to repeat several simulations for verification and calibration

114 purposes, we improved time performance through a hybrid implementation using MPI

115 (Message Passing Interface) and threads by OpenMP (Open Multi-Processing) (Aochi \& 116 Dupros, 2011). It takes 40-minute and an 8-hour runs for coarse and medium-sized grids 117 respectively, on the 128 processors (16 nodes $\times 8$ cores) on JADE at CINES, the French 118 national computing centre. It takes about 18 hours for the finer grid on the 256 processors (32 119 nodes x 8 cores, namely 32 MPI sub-domains x 8 OpenMP threads).

\section{3D Structural Models}

\section{Geological Features}

In this section, we will be explaining three 3D structure models we use in this study.

124 Their key features are summarized in Table 1, and the cross-sections of each model are shown

125 on Figure 3. The flat part of this region and the folded hills in between, as well, are composed

126 of thick sedimentary layers. Conversely, the surrounding mountains to the south and east are 127 characterized by rocks. The complex lateral variations in basement structure along the NE-SE 128 fault striking are ascribed to Miocene rifting during the opening stage of the Sea of Japan and

129 the subsequent shortening of the crust (Okamura et al., 1995; Kato et al., 2009). Because the 130 Mw 6.6 Chuetsu earthquake in 2004 occurred $30 \mathrm{~km}$ southeast of the area ruptured in 2007, 131 this region is recognized as an active fracture zone or strain concentration zone, which had 132 been identified through structural geology (Okamura et al., 1995) and GPS observations 133 (Sagiya et al., 2000). Because this area exhibits complex 3D structures, the velocity structure 134 must be correctly reproduced if we are to generate sound synthetic ground motions. 


\section{The ERI Model}

The first model (hereinafter referred to as the "ERI" model) is built by P- and S-wave

138 travel time Double-Difference tomography from aftershock observations on land and at the

139 sea bottom (Kato et al., 2008; Shinohara et al., 2009; Kato et al., 2009). A relocated

140 aftershock distribution is provided as well, based on the ERI model. The minimum grid

141 interval is $3 \mathrm{~km}\left(\mathrm{~N} 125^{\circ} \mathrm{E}\right) \times 5 \mathrm{~km}\left(\mathrm{~N} 35^{\circ} \mathrm{E}\right)$ x $3 \mathrm{~km}$ (vertical). The minimum S-wave velocity

142 (Vs) obtained is $866 \mathrm{~m} / \mathrm{s}$.

\section{The NIED Model}

The second model (hereinafter referred to as the "NIED" model) is taken from

146 Fujiwara et al. (2009) and is available on the J-SHIS website (Japan Seismic Hazard

147 Information Station: http://www.j-shis.bosai.go.jp). The area of interest is largely the same as

148 Hikima et al. (2007), also based on Fujiwara et al. (2006). Hikima et al. (2007) associate the

149 preliminary structural model with the seismic reflection results, calibrate the structure (layer

150 depths) beneath each station by means of the observed $\mathrm{H} / \mathrm{V}$ spectrum (1D tuning) and also

151 tune up the structure along cross-sections between source and receiver, particularly for the

152 aftershocks of the 2004 Chuetsu earthquake (2D tuning). The file (J-SHIS) provided is

153 described in terms of depth to the layer boundaries at mesh nodes of $45^{\prime \prime}$ in longitude and 30"

154 in latitude (the $3^{\text {rd }}$ mesh for land planning in Japan), namely about a $1 \mathrm{~km} \mathrm{x} 1 \mathrm{~km} \mathrm{mesh}$. It

155 contains 32 layers between the surface and the basement characterized by an S-wave velocity

156 (Vs) of $3300 \mathrm{~m} / \mathrm{s}$, but many of these are not present in the region of concern. The minimum

$157 \quad \mathrm{Vs}$ is set at $350 \mathrm{~m} / \mathrm{s}$.

158

159 The GSJ Model 
The third model, referred to in this paper as the "GSJ" model, is presented in

161 Sekiguchi et al. (2009). They improved the earlier NIED model (Fujiwara et al., 2006) for the

162 Niigata area by carefully calibrating layer depths and rock parameters based on seismological

163 observations and taking into account the regional dependency of material parameters. The file

164 (appended CD-ROM of Sekiguchi et al., 2009) provides the depth of layer boundaries at mesh

165 nodes of 0.00625 degrees longitude and 0.004167 degrees latitude, i.e., about a $0.5 \times 0.5 \mathrm{~km}$

166 mesh. Model 2 designated in their CD-ROM contains 50 layers above the Moho. Because the 167 parameters beneath the basement $(\mathrm{Vs}=3300 \mathrm{~m} / \mathrm{s})$ are not supplied, we have used those from 168 their previous study in other regions, the central part of Japan (Sekiguchi \& Yoshimi, 2010).

\section{Comparison}

The original features of each model are provided in the corresponding references.

172 Figure 3 shows the cross-sections for these three models derived from the numerical

173 simulations. We note that while there are many layers in the NIED and GSJ models, all of 174 them are not always present at the finite difference grid point. We then interpolate the 175 material parameters by averaging (Graves, 1996) instead of estimating precisely the interface 176 plane between the finite difference grids (Moczo et al., 2002). While uncertainties linked to 177 the numerical processing remain on the scale of a calculation grid, the models used do 178 adequately represent characteristic features in Figure 3. The three models are visually similar 179 in terms of the shape of the basin structure. Although the tomography study (the ERI model) 180 is carried out independently, it does detect the basin structure (low velocity zone) well. As the 181 ERI model is inverted from dense observation data mainly above the aftershock area, the 182 resolution toward the north $(\mathrm{Y}=20 \mathrm{~km})$ is not good enough to be comparable with the other 183 two models. The NIED and GSJ models are similar, but the bedrock depth seems different: the NIED model is generally deeper. 


\section{Aftershock simulations}

187

188

189

190

191

192

193

194

195

196

197

198

\section{Model settings}

In order to examine the structural models in detail, we begin by simulating some small earthquakes. We chose two aftershocks of the 2007 Niigata-ken Chuetsu-oki earthquake that were well located by Kato et al. (2008) and Shinohara et al. (2008) and also have mechanisms obtained by the F-net broadband seismograph network (http://www.fnet.bosai.go.jp). Table 2 summarizes the source parameters. The hypocental depths given by the two catalogues differ by a few kilometres, although the epicenters are relatively well determined. The seismicity distribution in this area is often shallower than that routinely obtained (cf., the progress report of the Japanese national project on the observation along the strained zone, MEXT, 2010). We impose a smooth bell-shaped source time function (cubic B-spline function) of a 0.5 second duration at the hypocenter (Figure 4), which is reasonable for events of Mw 4.4. We simulate these sources for each of the three geological models.

Before discussing the simulation results, a question may be raised concerning the quality of finite difference simulations. In Appendix, we have provided our synthetic comparisons between the finite difference and spectral element methods using the ERI model for the first aftershock. It is thus found that the numerical simulations are reliable enough to provide the ground motion under the given model and conditions.

\section{Near-Field Ground Motion}

Figure 4 shows the comparison at station KZK (F-net) using the three structural models, all of which are simulated with $\Delta s=100 \mathrm{~m}$. This station is located at a depth of $60 \mathrm{~m}$ on terrain characterized as rocky, not only locally but also regionally to a certain extent. In the simulations, the event origin times are set at 0 . We align the observations for the origin time 
reported by the relocated earthquake catalogue (Table 2). The seismograms are not filtered at

211 this station. First we observe that the P-wave arrives simultaneously for all the cases (UD 212 component), but the S-wave arrival does differ somewhat. The ERI model, for which the 213 earthquakes are relocated, yields the best arrival time, whereas the other two models, NIED 214 and GSJ, display a delay of a few seconds (EW and NS components). Then, the two models 215 predict much longer and stronger ground shaking than observations in the later phases. This 216 would tend to indicate that their S-wave structure might need to be better tuned up, supposing 217 that the relocated earthquake parameters are correct here. For this KZK station, the ERI model 218 appears to be better constrained, presumably thanks to their 3D tomography coverage from 219 the source area to the station. However, we find that the EW component of the first aftershock 220 (07/16) displays a clear discrepancy between the synthetics and the observation, even with 221 ERI model, as the later phases are those that become dominant in terms of amplitude. This issue is not perfectly resolved and represents a common tendency for this aftershock along the coastline (NIG018 and KK as well). The synthetics do not properly account for the later 224 phases, possibly due to the more complex layer that is shallower than the given resolution (3 $225 \mathrm{~km}$ in depth, see Table 1).

\section{The Regional Wave Field}

Figures 5 and 6 show the comparison at different stations for different structural models for Aftershocks 1 and 2 respectively. Each seismogram is aligned as was described above. The seismograms are filtered with a $0.1-0.5 \mathrm{~Hz}$ band-pass filter and only the EW component is shown; the response spectra for $5 \%$ damping are also compared. There are still difficulties in reproducing both arrivals and later phases in a satisfactory manner, since they must exhibit a correct velocity profile on the direct path (first arrivals) as well as in a larger

234 surrounding volume for the later phases. In this sense, it is not possible to determine whether 
one model is better than another at this stage insofar as none of them are perfect for a 236 particular study.

However, some remarks can be made, also briefly summarized in Table 3. First, some models are seen to generate later phases that are too large at some stations, for example, the

239 GSJ model at NIGH12. The first phase, on the other hand, is fairly accurately rendered by 240 some models at most stations because the source and structure parameters are relatively well 241 established. We note some time shift in phase among the simulations and/or with respect to 242 the observation, at NIG004 and NIG025 among others, for example. This indicates that 243 further improvement may be achieved both in source and structural parameters, but this is not 244 this study's objective. Generally in the near field (cf., NIG018, NIGH11, NIG019, NIG017, 245 NIG016, counter-clockwise), where the propagation path is relatively simple, the 246 reproduction is quite good (especially Figure 6 for Aftershock 2). The response spectra 247 indicate the validity of the average response around the given stations. The simulation of 248 Aftershock 2 is found to be more consistent with the observation than that of Aftershock 1, 249 for which the simulations underestimate the long-period potion of the spectra at the nearest 250 station along the coast. This once again indicates that Aftershock 1 could afford further 251 calibration, probably of the focal depth and/or local structure around the source. In the 252 Kashiwazaki area in the simulation of Aftershock 2, station KZK (a rock site) is well 253 reproduced by the ERI model, while NIG018 (a soil site) is rendered best by the GSJ model, 254 reflecting local geological conditions.

\section{Discussion}

As already stated, the simulations are sometimes not as satisfactory for Aftershock 1. 258 Reasons for this could be that the source parameters are not well constrained or the local 259 structure for this earthquake is not precise enough. As the arrival times of the main phases are 
260 fairly good in different directions, the earthquake location appears reliable. Our next step, 261 then, was to invert Aftershock 1's focal mechanism using the ERI model and apply the 262 neighbourhood algorithm so as to generate a wide range of parameters without prior 263 information. After several trials using different stations and different components of the 264 seismograms, we always obtain a focal mechanism of approximately (strike, dip, rake) = $265\left(181^{\circ}, 65^{\circ}, 84^{\circ}\right)$, which differs from the reference solution only by 10 degrees. We may 266 accordingly conclude that the focal mechanism obtained is stable. The remaining open question is: how is it possible to have only one component that does not fit well?

\section{Mainshock simulations}

\section{Finite source models and simulations in $1 D$ layered models}

In this section, we chose two finite source models, both involving a southeast dipping reverse fault. Figure 7 shows the projection of the fault plane and the final slip obtained and Table 4 summarizes their characteristics. We used model B (southeast dipping) drawn from Aoi et al. (2008). The model initially obtained by Hikima and Koketsu (2007) was recently integrated into the work of Miyake et al. (2010). We found hypocental locations only about 1 km apart; however, due to differences in strike and dip, the disrepancy between the two fault planes is greater. Both models are analysed using available near-field strong ground motion. The only significant difference is that Hikima and Koketsu (2007) used the nearest station data (KK) at the Kashiwazaki-Kariwa nuclear power plant, while Aoi et al. (2008) do not.

280 Note that the data at NIG018 seems to have been distorted by the strong liquefaction at the 281 site, and the record at KZK is saturated for the mainshock. In Figure 8, we show the source 282 time function for each model, which is not retrieved directly from their provided file but rather is based on our input file after changing the file format to make it compatible with our 
code (e.g. Figure 2). This is important so as to verify our simulations and also for our

285 subsequent discussion of how the strong ground motion is radiated.

We first entered these input files in the simple 1D structure and verified that the source

model was properly taken into account. Aoi et al. (2008) introduced the moving source effect

when calculating their Green's functions semi-theoretically. We approximated this effect numerically by means of 5 x 5 sub-sub-point sources distributed on each sub-fault in our

290 finite difference simulation, as we already demonstrated in other earthquakes (e.g. Aochi et al., 2010). For this earthquake, we observe that the moving source effect is also visible at NIG004.

Table 5 gives the 1D velocity structure models derived from the inversions. These are representative of their reference velocity models to a certain extent, but it should be borne in

294 mind that the two inversions adopt different $1 \mathrm{D}$ velocity models independently calibrated at 295 every station, that is, the wave field we simulate here does not simultaneously represent all 296 the stations. We chose NIG004 and NIG016 for, as seen on Figure 9, the 1D structure from 297 Aoi et al. corresponds better to NIG004 and that from Hikima \& Koketsu to NIG016. The 298 compared ground motions were filtered between 0.1 and $0.5 \mathrm{~Hz}$ and calculated with $\Delta s=200$ $299 \mathrm{~m}$. The origin time is set at 10:13:22.16 (JST) for the observation, and the simulations start at $300 \mathrm{t}=0$. Our synthetic ground motion for the Aoi et al. model is consistent with the observation at 301 NIG004. Note that their inversion uses only 14 seconds, consisting mainly of the S-wave. 302 This confirms our implementation of the finite source models. At NIG016, the synthetic 303 motion from Hikima \& Koketsu reproduces the characteristic waveforms, especially for the 304 vertical component, with time shift of a few seconds. Such a time shift is common in 305 inversions, as the location of the hypocenter and the origin time are not always the same. 306 These verifications not only confirm our numerical implementations but also reflect some of 307 the inversion procedures. 
We first carried out simulations in 1D layered models. The reason for this is that most seismological and seismic hazard applications still call on this simple structure except for a few well-known areas in the world, such as southern California, southeastern Japan and Taiwan. In practice, the two source models that were adopted are deduced using this approximation. It accordingly is worthwhile to observe the effects of a $3 \mathrm{D}$ structure with respect to the 1D layered models.

\section{Simulations in 3D structure models}

It is not at all evident that the combination of any 3D structure model with any finite

317 source model obtained within a 1D layer model can coherently reproduce the observation, 318 although this procedure is recommended to predict the ground motion for scenario

319 earthquakes intended for use in quantitative seismic hazard studies. It is thus useful now to 320 seek to obtain the characteristic ground motions at different stations and discuss the capability 321 and limitations of the given models.

Figures 10 and 11 show the comparison of a number of synthetic ground motions and the observations at each station for both source models, bearing in mind the fact that the duration of the source process is approximately 15 seconds (Figure 8). The ground motions correspond to the EW component alone and are filtered between 0.1 and $0.5 \mathrm{~Hz}$, because the comparison using this component is enough representative. The ERI model is simulated with $\Delta s=200 \mathrm{~m}$ and the others with $\Delta s=100 \mathrm{~m}$.

Let us examine the stations in the near field (NIG018, NIGH11, NIG019, NIG017, 329 NIG016, counter-clockwise). The source model from Aoi et al. properly reproduces the 330 waveforms for the first main phases (about 15 seconds) at NIG016 and NIG019, and the one 331 from Hikima \& Koketsu is well suited to NIG017. This coincidence implies that the 1D 332 structural model used in their inversions may be briefly consistent along the concerned cross- 
section. Looking at later phases, we also note that goodness of fit is influenced more by the

334 structure than by the source. Both source models reproduce the later phases properly at 335 NIGH11, NIG019, and NIG017 with the NIED and GSJ structures but not with the ERI 336 structure. For NIG018, the three characteristic main pulses are clearly visible, especially in 337 the combination of the NIED structure and the Hikima \& Koketsu source model, though the 338 amplitude is much smaller in the synthetics. An additional study of nonlinear soil dynamics 339 could be conducted for this station using the synthetic seismograms as input ground motion, 340 but this is beyond the scope of our study.

341 Now let us look at the stations at moderate distance (NIG025, NIG024, NIGH12, 342 NIGH09, NIGH07, NIG011, NIG010, and NIG004). The ERI structure, for example, 343 produces much larger later phases at NIG004, NIG025 and NIGH07, not noticeable in earlier 344 comparisons of aftershocks (Figures 5 and 6), implying that the validity of structure should be 345 evaluated taking into account the frequency content of the source time function. Furthermore, 346 it is noted that the observed motion is much larger (spectra over all the frequency range) than 347 any synthetics at NIG010 and NIG011, and this discrepancy is more obvious for the 348 mainshock than for the aftershock. This indicates that the mainshock generates much larger 349 surface waves than the aftershock.

350 In this section, we combine different source and structure models to simulate the 351 ground motions. For the same reason already cited in the previous section for the aftershock 352 simulations, it is impossible to determine whether one model is better than the others, for this 353 depends on which aspect one is looking at, since no combination is currently perfect.

\section{Discussion}

The numerical simulations reflect the current level of seismological knowledge

357 concerning this earthquake. For practical reasons, it is thus important to study the variations in 
the calculated result from the standpoint of seismic hazard studies. It was predictable that the

359 simulations for the mainshock would not fit the data well in terms of waveforms because the

360 fault models are derived supposing some 1D structures: this may be the limit of our

361 seismological knowledge. However, for engineering purposes, the variation of the simulated

362 ground motions is meaningful. Figures 12 and 13 show the PGV (Peak Ground Velocity) map

363 (different frequency ranges up to $0.5 \mathrm{~Hz}$ ) for the three structural and two source models. Each

364 source model is also calculated with the reference 1D velocity models (Table 5). As observed

365 in the seismograms (Figures 10 and 11), the source model from Hikima \& Koketsu yields

stronger ground motion near the coastline rather than offshore; furthermore, the PGV

367 generated from the model by Aoi et al. is centred along the blind fault trace. This latter feature

368 is common for thrust fault earthquakes due to the geometry. In other words, it is confirmed

369 that the model from Hikima \& Koketsu integrates some complexity in the rupture process that

370 is acquired particularly from the very near-source records such as the station at the

371 Kashiwazaki-Kariwa nuclear power plant. On the other hand, different 3D structure models

372 briefly give the similar characteristic. The expansion of the green area is consistent with the

373 existence of low-velocity sediments beneath the Sea of Japan between Sado Island and the

374 mainland as well as in the Niigata plain (see topographical map in Figure 3), which cannot be 375 seen in 1D structure modelling. The amplification under the sea is stronger for the ERI 376 structural model, which is the only model constrained from the OBS stations, although the 377 shallow sediment layer under the sea is difficult to evaluate. Cirella et al. (2008) also obtained 378 the finite source model by the joint inversion of strong motion and GPS data and show their 379 forward modelling result in the 1D structure. Concerning the ground motion pattern above the 380 fault plane, the model by Cirella et al. (2008) is closer to the one by Hikima \& Koketsu used 381 here. Kawabe and Kamae (2010) simulate the wave propagation in a 3D structure model 382 provided by JNES (Japan Nuclear Energy Safety Organization, internal report, 2005) focusing 
on the Kashiwazaki-Kariwa nuclear plant. They used a characterized, simple source model with three asperities and obtained the comparable synthetic ground motions (frequency range $0.05-1.6 \mathrm{~Hz}$ ), strongly affected by these asperities as well as by their local 3D structure. The JNES model may be more precise around this point of interest but remain essentially local in scope. Thus for the purposes of a regional discussion as provided in this paper, this model should be further compiled with other models.

We are also interested in other engineering parameters which characterize the ground motion. Figure 14 shows the comparison of PGV values (up to $0.5 \mathrm{~Hz}$ ) at K-net and KiK-net stations. In terms of PGV (one of the most simple engineering parameters), we can confirm that the simulations are globally consistent with observations within this frequency range except for NIG018, and probably for other stations where later phases are not well modelled (e.g. NIG010 in the ERI structure). This is because the PGV is less sensitive to the details of the rupture process, being mainly affected by macroscopic parameters like fault location, fault geometry, rupture directivity, rupture velocity, and final magnitude. In this sense, both source models are suitable for simulating regional ground motion around the fault.

As already seen, this earthquake is an example in which it is difficult to quantitatively reproduce the waveforms. One possible reason is that the complex 3D structure masks the real features of this earthquake. Many kinematic inversions adopt the southeast dipping fault geometry, but this orientation is not the only one sustainable. Aochi and Kato (2010) demonstrate the possibility of a dynamic rupture transfer from a northwest dipping sub-fault to another southeast dipping sub-fault. The two models we used in this study differ in fault 404 orientation, in the position of asperities and in rupture timing, and actually do not fit the same stations. Our study reported in this paper does not aim to calibrate the parameters, but the computing performance we have achieved will allow us to investigate further the source 
subsurface structure obtained through fine tomography might not be sufficient to reproduce

409 observed strong motions, nor those created through the use of both geologic and geophysical

410 data. For some stations suffered from the strong ground motion (c.f. NIG018), it will be

411 necessary to study by coupling with the nonlinear site effects at local level. We may conclude

412 that a combination of tomography and data compiling in velocity structure modelling are 413 called for.

414

\section{7. Conclusion}

416 Finite difference simulations of seismic wave propagation are carried out in the Niigata area,

417 Japan, for the $2007 \mathrm{Mw}$ 6.6 Niigata-ken Chuetsu-Oki earthquake at low frequencies. Some of 418 the calculations are extended up to $1 \mathrm{~Hz}$ considering the minimum velocity in the medium of $419350 \mathrm{~m} / \mathrm{s}$. However we limit our discussion to $0.5 \mathrm{~Hz}$ throughout this study because of lack of 420 precision in the model. We test three 3D structure models, all of which are built differently in 421 various studies. From the aftershock simulations, it is seen that none of the models are 422 uniform in their resolution and precision in this region, as the later phases are poorly reproduced in some more distant stations. The model based on 3D tomography (ERI model) is good enough for the near field in terms of body waves (arrival time), but its precision for shallow sediment layers is insufficient to reproduce the later phases properly, while the other models (NIED and GSJ models), based on various 1D/2D profiles and geological

427 interpretation, work well for the site response, but do sometimes cause a time shift in phases.

428 For the mainshock simulations, we adopt two different finite source models (Aoi et al., 2008;

429 Hikima and Koketsu, 2008), which differ in the near-field ground motion, especially above

430 the fault plane (but under the sea) and also along the coastline. It is found that each model is

431 calibrated differently for the given stations. For engineering purposes, the variation observed 432 in simulated ground motion is significant, but for seismological purposes, further parameter 
433 calibration is desirable and possible for such a complex 3D case using current high

434 performance computing.

\section{Acknowledgments}

437 This work is carried out mainly in the framework of the French national ANR DEBATE 438 project (DEvelopment of Broadband Accleration Timeseries for Engineers; 2009-2012). We 439 thank all the colleagues for making available their numerical results: Drs. A. Kato, S. Aoi, H. 440 Sekiguchi, K. Hikima and K. Koketsu. Many fruitful discussions were held with Profs. Raul 441 Madariaga, Dr. Fabian Bonilla and Prof. Hiroshi Kawase, and Dr. Ken'ichi Tsuda from the 442 DEBATE project. We thank Prof. Peter Moczo and Dr. Eiichi Fukuyama for improving the manuscript. We also express our appreciation for the data provided by K-net, KiK-net, and F-

444 net of the National Research Institute for Earth Science and Disaster Prevention. HA thanks NIED for his invitation to Japan in October 2010. MY thanks AIST-GSJ for funding his visit to BRGM in 2009-2010. Part of the simulations were carried out at the super computing center (CINES) in France.

\section{References}

1. Aochi, H. and F. Dupros, Dynamic rupture propagation to seismic wave radiation in advance computing seismology, in the proceedings of the $1^{\text {st }}$ International Workshop on Advances in High-Performace Computational Earth Sciences: Applications and Frameworks (IHPCES), Tsukuba, Japan, June, 2011.

2. Aochi, H., V. Durand and J. Douglas, Influence of super-shear earthquake rupture models on simulated near-source ground motion from the 1999 Izmit (Turkey) earthquake, Bull. Seism. Soc. Am., in press, 2011. 
3. Aochi, H. and A. Kato, Dynamic rupture of crosscutting faults: A possible rupture process for the 2007 Mw 6.6 Niigata-ken Chuetsu-Oki earthquake, J. Geopohys. Res., 115, B05310, doi:10.1029/2009JB006556, 2010.

4. Aochi, H. and R. Madariaga, The 1999 Izmit, Turkey, earthquake: Nonplanar fault structure, dynamic rupture process, and strong ground motion, Bull. Seism. Soc. Am., 93, 1249-1266, 2003.

5. Aoki, Y. M. Furuya and T. Kato, Coseismic deformation due to the 2007 Chuetsu-oki earthquake (Mw=6.8), Earth Planets Space, 60, 1075-1080, 2008.

6. Aoi, S., H. Sekiguchi, N. Morikawa and T. Kunugi, Source process of the 2007 Niigata-ken Chuetsu-oki earthquake derived from near-fault strong motion data, Earth Planets Space, 60, 1131-1135, 2008.

7. Chaljub, E., P. Moczo, S. Tsuno, P. Y. Bard, J. Kristek, M. Kaser, M. Stupazzini, M. Kristekova, Quantitative comparison of four numerical predictions of 3D ground motion in the Grenoble Valley, France, Bull. Seism. Soc. Am., 100, 1427-1455, 2010.

8. Collino, F. and C. Tsogka, Application of the perfectly matched absorbing layer model to the linear elastodynamic problem in anisotropic heterogeneous media, Geophysics, 66, 294-307, 2001.

9. Day, S. M., J. Bielak, D. Dreger, R. Graves, S. Larsen, K. B. Olsen and A. Pitarka, Tests of 3D elastodynamic codes: Final report for Lifelines project 1A01, technical report for Pacific Earthquake Engineering Research Center, 2001.

10. De Martin, F., Verification of a spectral element method code for the Southern California Earthquake Center LOH.3 viscoelastic case, Bull. Seism. Soc. Am., 101, doi:10.1785/0120100305, 2011.

11. Douglas, J. and H. Aochi, A survey of techniques for predicting earthquake ground motions for engineering purposes, Surv. Geophys, 29, 187-220, 2008. 

multithreading for the efficient simulation of 3D seismic wave propagation, in the proceeding of the 11th International Conference on Computational Science and Engineering, San Paulo, Brazil, 2008.

13. Fujiwara, H., S. Kawai, S. Aoi, N. Morikawa, S. Senna, N. Kudo, M. Ooi, K. X.-S. Hao, Y. Hayakawa, N. Toyama, H. Matsuyama, K. Iwamoto, H. Suzuki and Y. Liu, A study on subsurface structure model for deep sedimentary layers of Japan for strongmotion evaluation, Technical note of the National Research Institute for Earth Science and Disaster Prevention, Tsukuba, Japan, no. 337, 2009 (in Japanese). Suzuki and Y. Hayakawa, A subsurface structure modelling of whole of Japan for strong-motion evaluation, in the proceeding of the $12^{\text {th }}$ Japan Earthquake Engineering Symposium, 1466-1469, 2006 (in Japanese with English abstract).

15. Furumura, T. and T. Saito, An integrated simulation of ground motion and tsunami for the 1944 Tonankai earthquake using high-performance super computers, Journal of Disaster Research, 4, 2, 118-126, 2009.

16. Hikima, K. and K. Koketsu, Source process of the 2007 Chuetsu-oki earthquake inferred from far field waveforms and strong motions, Seismol. Soc. Japan, Fall Meeting, Abstract P1-085, 2007 (in Japanese).

17. Hikima, K., H. Suzuki, H. Miyake, T. Furumura and K. Koketsu, Construction of the 3-D velocity structure model around Niigata district, Seismol. Soc. Japan, Fall Meeting, Abstract D22-01, 2007 (in Japanese).

18. Kato, A., E. Kurashimo, T. Igarashi, S. Sakai, T. Iidaka, M. Shinohara, T. Kanazawa, 506 
devastating intraplate earthquakes, Geophys. Res. Lett., 36, L05301, doi:10.1029/2008GL036450, 2009.

19. Kato, A., S. Sakai, E. Kurashimo, T. Igarashi, T. Iidaka, N. Hirata, T. Iwasaki, T. Kanazawa and Groupe for the aftershock observations of the 2007 Niigataken Chuetsu-oki earthquake, Imaging heterogeneous velocity structures and complex aftershock distributions in the source region of the 2007 Niigataken Chuetsu-oki Earthquake by a dense seismic observation, Earth Planets Space, 60, 1111-1116, 2008.

20. Kawabe, H. and K. Kamae, Source modelling and 3D ground motion simulation of the 2007 Niigataken Chuetsu-oki earthquake (Mj6.8), in the proceeding of the $13^{\text {th }}$ Japan Earthq. Eng. Symposium, Tsukuba Japan, November 2010 (in Japanese with English abstract).

21. Komatitsch, D. and R. Martin, An unsplit convolutional perfectly matched layer improved at grazing incidence for the seismic wave equation, Geophysics, 72, SM155SM167, 2007.

23. Levander, A. R., Fourth-order finite-difference P-SV seismograms, Geophysics, 53, 1425-1436, 1988.

22. Kristekova, M., J. Kristek and P. Moczo, Time-frequency misfit and goodness-of-fit criteria for quantitative comparison of time signals, Geophys. J. Int., 178, 813-825, 2009.

24. Miyake, H., K. Koketsu, K. Hikima, M. Shinohara and T. Kanazawa, Source fault of the 2007 Chuetsu-oki, Japan, earthquake, Bull. Seism. Soc. Am., 100, 384-391, 2010.

25. Moczo, P., J. Kristek, V. Vavrycuk, R. J. Archuleta, and L. Halada, 3D heterogeneous staggered-grid finite-difference modelling of seismic motion with volume harmonic and arithmetic averaging of elastic moduli and densities, Bull. Seism. Soc. Am., 92, 3042-3066, 2002. 
26. Moczo, P., J. Kristek, M. Galis, P. Pazak and M. Balazovjech, The finite-difference and finite-element modelling of seismic wave propagation and earthquake motion, Acta Physica Slovaca, 57, 177-406, 2007.

27. Nishimura, T., M. Tobita, H. Yarai, S. Ozawa, M. Murakami, T. Yutsudo, M. Ishimoto, T. Umesawa, T. Toyofuku, S. Kawamoto, T. Amagai, M. Fujiwara, A. Suzuki, S. Enya, T. Sasaki, M. Yokokawa, S. Oomori, S. Tanoue, H. Ikeda, M. Nemoto, H. Suito, F. Hayashi, H. Une, M. Koarai and M. Tsuzawa, Crustal deformation and a preliminary fault model of the 2007 Chuetsu-oki earthquake observed by GPS, InSAR, and levelling, Earth Planets Space, 60, 1093-1098, 2008.

28. Okamura, Y., M. Watanabe, R. Morijiri, and M. Satoh, Rifting and basin inversion in the eastern margin of the Japan Sea, Isl. Arc, 4, 166-181, doi:10.1111/j.14401738.1995.tb00141.x, 1995.

29. Olsen, K. B., S. M. Day, L. Dalguer, J. Mayhew, Y. Cui, J. Zhu, V.M. Cruz-Atienza, D. Roten, P. Maechling, T.H. Jordan, and A. Chourasia, ShakeOut-D: Ground Motion Estimates Using an Ensemble of Large Earthquakes on the Southern San Andreas Fault With Spontaneous Rupture Propagation, Geophysical Research Letters 36 L04303, doi:10.1029/2008GL036832, 2009.

30. Pitarka, A. K. Irikura, T. Iwata, H. Sekiguchi, Three-dimensional simulation of the near-fault ground motion for the 1995 Hyogoken-nanbu, Japan, earthquake, Bull. Seism. Soc. Am., 88, 428-440, 1998.

31. Sagiya, T, S. Miyazaki, and T. Tada, Continuous GPS array and present-day crustal deformation of Japan, Pure and Applied Geophysics, 157, 2303-2322, 2000.

32. Sasetyan, K., Caractérisation du spectre de réponse en champ proche d'une faille par 556 simulation des mouvements forts du sol, PhD Thesis, University of Paris XI, France, 2007. 
33. Sekiguchi, H., M. Yoshimi, H. Horikawa, K. Yoshida, H. Suzuki, H. Matsuyama, M. Morino, F. Takizawa, and L. Ying, 3D subsurface structure model of the Niigata sedimentary basin, Geological Survey of Japan/AIST Annual report on Active fault and paleoearthquake researches, 9, 175-259, 2009 (in Japanese with English abstract).

34. Sekiguchi, H. and M. Yoshimi, Broadband ground motion reconstruction for the Kanto Basin during the 1923 Kanto earthquake, Pure and Applied Geophysics, doi:10.1007/s00024-010-0142-9, 2010.

35. Shinohara, M., T. Kanawaza, T. Yamada, K. Nakahigashi, S. Sakai, R. Hino, Y. Murai, A. Yamazaki, K. Obana, Y. Ito, K. Iwakiri, R. Miura, Y. Machida, K. Mochizuki, K. Uehira, M. Tahara, A. Kuwano, S. Amamiya, S. Kodaira, T. Takanami, Y. Kaneda and T. Iwasaki, Precise aftershock distribution of the 2007 Chuetsu-oki earthquake obtained by using an ocean bottom seismometer network, Earth Planets Space, 60, 1121-1126, 2008. 
572 Appendix: Comparison between finite difference and spectral element

\section{3 methods}

Finite difference simulations are widely used for practical applications, but their

575 quality is sometimes debated especially in the framework of synthetic benchmark tests (e.g.

576 Day et al., 2001; Chaljub et al., 2010). As pointed out by many researchers, the finite

577 difference scheme does not represent any interface correctly (free surface, faulting and

578 material interface) but always gives an approximate solution. In this study, we do not deal

579 explicitly with the interface plane in the numerical simulations even though the models

580 initially supplied (the NIED and GSJ models) are defined by layers. As none of the three

581 models are defined at the finite difference grids of calculation, estimating the material

582 interfaces at given points requires further assumptions.

583 In this appendix, we are describing a comparative test using the finite difference as

584 well as the spectral element methods (De Martin, 2011). We adopt the first example, namely

585 the ERI structure model for the first aftershock. In the spectral element scheme, the material

586 properties are interpolated at each of the GLL (Gauss-Lobatto-Legendre) points. The entire

587 domain is uniformly meshed with hexahedra, constrained by the lowest S-wave velocity. The

588 mesh is composed of 208,936 geometrical nodes, 196,425 hexahedra $1200 \mathrm{~m}$ in size in all

589 directions and 16,757 quadrangles for absorbing boundaries by paraxial approximation

590 different from our finite difference simulation. The polynomial order of the basic functions is

$591 \mathrm{~N}=4$, and the total number of degrees of freedom is 46 million (including the redundant GLL

592 at the interfaces between the CPUs). Also, the finite difference simulation here is carried out

593 with a grid spacing of $200 \mathrm{~m}$. 
Figure A1 shows the comparison of the seismograms at NIG004 filtered in the

595 frequency range between 0.1 and $0.5 \mathrm{~Hz}$ using the ERI model for Aftershock 1. Despite the

596 completely different numerical procedures, the overall waveforms are well enough

597 reproduced to allow the characteristics of the ground motion to be discussed. Figure A2

598 shows the goodness-of-fit (GOF; Kristekova et al., 2009) for the surrounding K-net stations

599 as a function of epicentral distance. This criterion provides a succinct evaluation of how

600 similar two signals are by a score assigned on a scale of 0 (poor) to 10 (excellent), and ranges

601 higher than 6.5 and 8.5 are considered as good and excellent, respectively. It is observed that

602 the GOD is better at closer distance because of the reduced influence of numerical dispersion

603 and of little impact from absorbing conditions. In fact, the worst station, NIG002, which is

604 qualified as fair (range 4.5 to 6.5), is very close to the model edge. Otherwise, it is confirmed

605 that the simulations are fair enough both in amplitude and phase for the purpose of our

606 discussions. 
608 Table 1: Characteristics of the three different structural models. See the references in the text.

\begin{tabular}{|c|c|c|c|}
\hline & ERI model & NIED model & GSJ model \\
\hline Area covered & $\begin{array}{l}\text { Around the area of the } 2004 \\
\text { and } 2007 \text { earthquakes }\end{array}$ & All of Japan & $\begin{array}{l}\text { Niigata area } \\
\text { measuring about } 200 \\
\mathrm{~km} \text { x } 200 \mathrm{~km}\end{array}$ \\
\hline $\begin{array}{l}\text { Principal data } \\
\text { included }\end{array}$ & $\begin{array}{l}\text { P- and S-wave tomography } \\
\text { of the aftershock }\end{array}$ & $\begin{array}{l}\text { Seismic reflection, } \\
\text { geological } \\
\text { interpretation, 1D } \\
\text { tuning, 2D tuning }\end{array}$ & $\begin{array}{l}\text { NIED model, } \\
\text { geological } \\
\text { interpretation, } \\
\text { geophysical borehole } \\
\text { data, 1D tuning }\end{array}$ \\
\hline $\begin{array}{l}\text { Given } \\
\text { resolution }\end{array}$ & $\begin{array}{l}3 \mathrm{~km}\left(\mathrm{~N} 35^{\circ} \mathrm{E}\right) \times 5 \mathrm{~km} \\
\left(\mathrm{~N} 125^{\circ} \mathrm{E}\right) \times 3 \mathrm{~km} \text { at least }\end{array}$ & $\begin{array}{l}45^{\prime \prime} \text { in longitude and } \\
30^{\prime \prime} \text { in latitude }\end{array}$ & $\begin{array}{l}0.00625 \text { degrees in } \\
\text { longitude and } \\
0.004167 \text { degrees in } \\
\text { latitude }\end{array}$ \\
\hline Vs minimum & $866 \mathrm{~m} / \mathrm{s}$ & $350 \mathrm{~m} / \mathrm{s}$ & $400 \mathrm{~m} / \mathrm{s}$ \\
\hline $\begin{array}{l}\text { Given } \\
\text { property }\end{array}$ & Vp, Vs by point & $\mathrm{Vp}, \mathrm{Vs}, \rho$ by layer & $\mathrm{Vp}, \mathrm{Vs}, \rho$ by layer \\
\hline
\end{tabular}

609

610 
611 Table 2: Source parameters of the aftershocks used in the simulations. The relocated

612 hypocentral parameters are based on Kato et al. (2008) and Shinohara et al. (2008). The focal 613 mechanisms are obtained routinely by F-net of NIED.

614

\begin{tabular}{|l|l|l|}
\hline & Aftershock 1 & Aftershock 2 \\
\hline Origin Time (JST) & $2007 / 07 / 1621: 08: 1.86$ & $2007 / 07 / 1816: 53: 5.01$ \\
\hline Relocated & $37.4983^{\circ} \mathrm{N}, 138.6147^{\circ} \mathrm{E}, 15.413$ & $37.4327^{\circ} \mathrm{N}, 138.5943^{\circ} \mathrm{E}, 16.880$ \\
\hline hypocenter & $\mathrm{km}$ & $\mathrm{km}$ \\
\hline houtinely obtained & $38.5088^{\circ} \mathrm{N}, 138.6297^{\circ} \mathrm{E}, 11 \mathrm{~km}$ & $37.4418^{\circ} \mathrm{N}, 138.6153^{\circ} \mathrm{E}, 20 \mathrm{~km}$ \\
\hline Mw & & \\
\hline Focal mechanism & $187^{\circ} / 54^{\circ} / 70^{\circ} ; 39^{\circ} / 41^{\circ} / 115^{\circ}$ & $39^{\circ} / 62^{\circ} / 95^{\circ} ; 208^{\circ} / 29^{\circ} / 80^{\circ}$ \\
(strike/dip/rake) & & \\
\hline
\end{tabular}

615

616 
617 Table 3: Brief summary of characteristics of the three 3D structural models from the

618 aftershock simulations.

\begin{tabular}{|l|l|l|}
\hline Model & Positive characteristics & Aspects to be improved \\
\hline ERI & Synthetics at near-field rock site, & Finer shallow structure, larger area \\
& especially in the south & \\
\hline NIED & Synthetics at near-field soil site, & Parameters in shallower soft layers, \\
& $\begin{array}{l}\text { Synthetics at near-field soil site, } \\
\text { Good site response generally, }\end{array}$ & Same as above \\
& $\begin{array}{l}\text { similar to NIED } \\
\end{array}$
\end{tabular}

619 
620 Table 4: Characteristics of the finite fault models used in this study. Some parameters were

621 not specified by Hikima and Koketsu (2007), but we have supplied an estimated condition

622 indicated in the blank.

\begin{tabular}{|l|l|l|}
\hline Model & Aoi et al. & Hikima \& Koketsu \\
\hline Reference & Model B from Aoi et al. $(2008)$ & Hikima \& Koketsu (2007) \\
\hline Hypocentral location & $37.54^{\circ} \mathrm{N}, 138.61^{\circ} \mathrm{E}$ & $37.54014^{\circ}, 138.62653^{\circ} \mathrm{E}$ \\
\hline Focal depth & $8.9 \mathrm{~km}$ & $10 \mathrm{~km}$ \\
\hline Fault geometry & Strike N49 $\mathrm{E}$, dip $42^{\circ}$ & Strike N38 $\mathrm{E}$, dip $34^{\circ}$ \\
\hline Total seismic moment & $1.62 \times 10^{19} \mathrm{~N} . \mathrm{m}$ & Not specified $\left(1.02 \times 10^{19} \mathrm{~N} . \mathrm{m}\right)$ \\
\hline Sub-fault number & $15(\mathrm{strike}) \mathrm{x} 12(\mathrm{dip})$ & 15 (strike) $\mathrm{x} 9$ (dip) \\
\hline Sub-fault size & $2 \mathrm{~km} \times 2 \mathrm{~km}$ & 2 km x 2 km \\
\hline Source time discretization & 6 multi-windows & 7 multi-windows \\
\hline Rake & Free in each window & Free in each window \\
\hline Source time function & A smoothed ramp function & Unknown (Ramp function) \\
\hline Moving rupture effect & Yes & Unknown (No) \\
\hline
\end{tabular}


625 Table 5: 1D structure models used for the simulations of this study. (a) For Aoi's model, (b) 626 for Hikima \& Koketsu's model.

$627 \quad$ (a)

\begin{tabular}{lllll}
\hline $\begin{array}{l}\text { Depth of the top } \\
\text { of the layer }[\mathrm{km}]\end{array}$ & $\mathrm{Vs}[\mathrm{m} / \mathrm{s}]$ & Density $\left[\mathrm{kg} / \mathrm{m}^{3}\right]$ & $\mathrm{Q}$ (attenuation) \\
\hline 0.0 & 4600 & 3090 & 2600 & 300 \\
1.383 & 5900 & 3300 & 2700 & 300 \\
13.632 & 6700 & 3800 & 2900 & 500 \\
27.533 & 7700 & 4300 & 3250 & 500 \\
\end{tabular}

628

629 (b)

\begin{tabular}{lllll}
\hline $\begin{array}{l}\text { Depth of the top } \\
\text { of the layer }[\mathrm{km}]\end{array}$ & $\mathrm{Vp}[\mathrm{m} / \mathrm{s}]$ & Density $\left[\mathrm{kg} / \mathrm{m}^{3}\right]$ & Q (attenuation) \\
\hline 0.0 & 2286.806 & 1020.620 & 2057.361 & 100 \\
0.5 & 2570.792 & 1238.071 & 2114.158 & 100 \\
1.0 & 2933.326 & 1517.943 & 2186.665 & 100 \\
1.5 & 3091.167 & 1639.359 & 2218.233 & 100 \\
2.0 & 3259.370 & 2094.144 & 2251.874 & 100 \\
3.0 & 3682.388 & 2330.547 & 2336.478 & 100 \\
4.0 & 4031.846 & 2490.645 & 2406.369 & 100 \\
5.0 & 4308.815 & 2753.608 & 2461.763 & 100 \\
6.0 & 4557.710 & 2891.243 & 2511.542 & 100 \\
7.0 & 4763.741 & 3107.153 & 2552.748 & 100 \\
8.0 & 5001.851 & 3403.074 & 2600.370 & 100 \\
9.0 & 5375.374 & 3767.530 & 2675.075 & 100 \\
\hline
\end{tabular}




\begin{tabular}{lllll}
10.0 & 5887.317 & 3403.074 & 2777.464 & 250 \\
14.0 & 6517.827 & 3767.530 & 2903.565 & 250 \\
20.0 & 6903.343 & 3990.372 & 2980.669 & 250 \\
33.0 & 7587.204 & 4262.474 & 3113.777 & 250 \\
\hline
\end{tabular}

630

631 
634 Figure 1: Map of the area surrounding the 2007 Niigata Chuetsu Oki earthquake. The star

635 represents the hypocentral location defined by Aoi et al. (2008). The black rectangle indicates

636 the projection of the fault plane according to Aoi et al. (2008). The grey rectangle indicates

637 the projection of the fault plane according to Hikima \& Koketsu (2008). The pink dots

638 represent the aftershocks relocated by Kato et al. (2008) and Shinohara et al. (2008) recorded

639 over the space of one month immediately after the mainshock. The triangles and names are

640 the seismograph stations from K-net, Kik-net, F-net and the Kashiwazaki-Kariwa nuclear

641 power plant operated by TEPCO (KK).

642

643 Figure 2: Schematic representation of the simulation procedure.

645 Figure 3: Cross-sections of different 3D structure models in the numerical simulations. See

646 the text for the details of each model, ERI, NIED and GSJ.

648 Figure 4: Comparison of synthetic and observed ground motion for the selected aftershocks

649 (Table 2) at station KZK using three different structural models. All the seismograms are not

650 filtered. The earthquake location and the given moment release function are shown at the top.

651 Response spectra are calculated at the bottom for the waveforms up to $0.5 \mathrm{~Hz}$.

652

653 Figure 5: Comparison of synthetic and observed ground motion for the first aftershock (Table

654 2) at different stations for each structure model. The ground motion is calculated over 60

655 seconds, then filtered between 0.1 and 0.5 seconds. The response spectra are also shown. 656 
657 Figure 6: Figure 5: Comparison of synthetic and observed ground motion for the second

658 aftershock (Table 2) at different stations for each structure model.

659

660 Figure 7: The two finite source models used in this study. Also see Table 4 for their

661 characteristics.

662

663 Figure 8: Source time function prepared as the input file for the numerical simulations. Each 664 panel is shown every $2 \mathrm{~km}$, as are their inversions. Red lines indicate the dip component (rake $90^{\circ}$ ) and blue ones represent the strike component (rake $0^{\circ}$ ) at each point.

666

667 Figure 9: Synthetic ground motions at NIG004 and NIG016 for the source models from Aoi et al. and Hikima \& Koketsu, simulated in 1D structure models, respectively. The seismograms are filtered between 0.1 and $0.5 \mathrm{~Hz}$.

670

671 Figure 10: Comparison of the synthetic ground motions at different stations for the Aoi source

672 model of the mainshock using the three different 3D structure models. The component is

673 East-West. The waveforms are filtered between 0.1 and $0.5 \mathrm{~Hz}$.

674

675 Figure 11: Comparison of the synthetic ground motions at different stations for the Hikima \& 676 Koketsu source model of the mainshock using the three different 3D structure models. The 677 component is East-West. The waveforms are filtered between 0.1 and $0.5 \mathrm{~Hz}$.

679 Figure 12: Map of peak ground velocity (PGV) for each component (x: east-west, y: north680 south, z: up-down) and the source model from Aoi et al. The seismograms are filtered up to 681 $0.5 \mathrm{~Hz}$. 
683 Figure 13: PGV map for the source model from Hikima \& Koketsu.

684

685 Figure 14: Comparison of horizontal (geometric mean) PGV for six simulations (see also

686 Figures 11 and 12). X symbols represent the observed values.

687

688 Figure A1: Comparison of synthetic seismograms at NIG004 calculated using the finite

689 difference and spectral element methods. The structure is the ERI model and the source is

690 Aftershock 1. The signals are filtered between 0.1 and $0.5 \mathrm{~Hz}$.

691

692 Figure A2: The goodness-of-fit between the two simulations at the surrounding K-net stations.

693 The seismograms are filtered between 0.1 and $0.5 \mathrm{~Hz}$, and the scores for both amplitude (left)

694 and phase (right) are shown for each component. The stations are aligned versus epicentral

695 distance. The reference for the score is taken for the spectral element method. The coherence

696 between two signals is excellent for a range of 8.5-10, good for 6.5-8.5 and fair for 4.5-6.5. 
697 Figure 1:

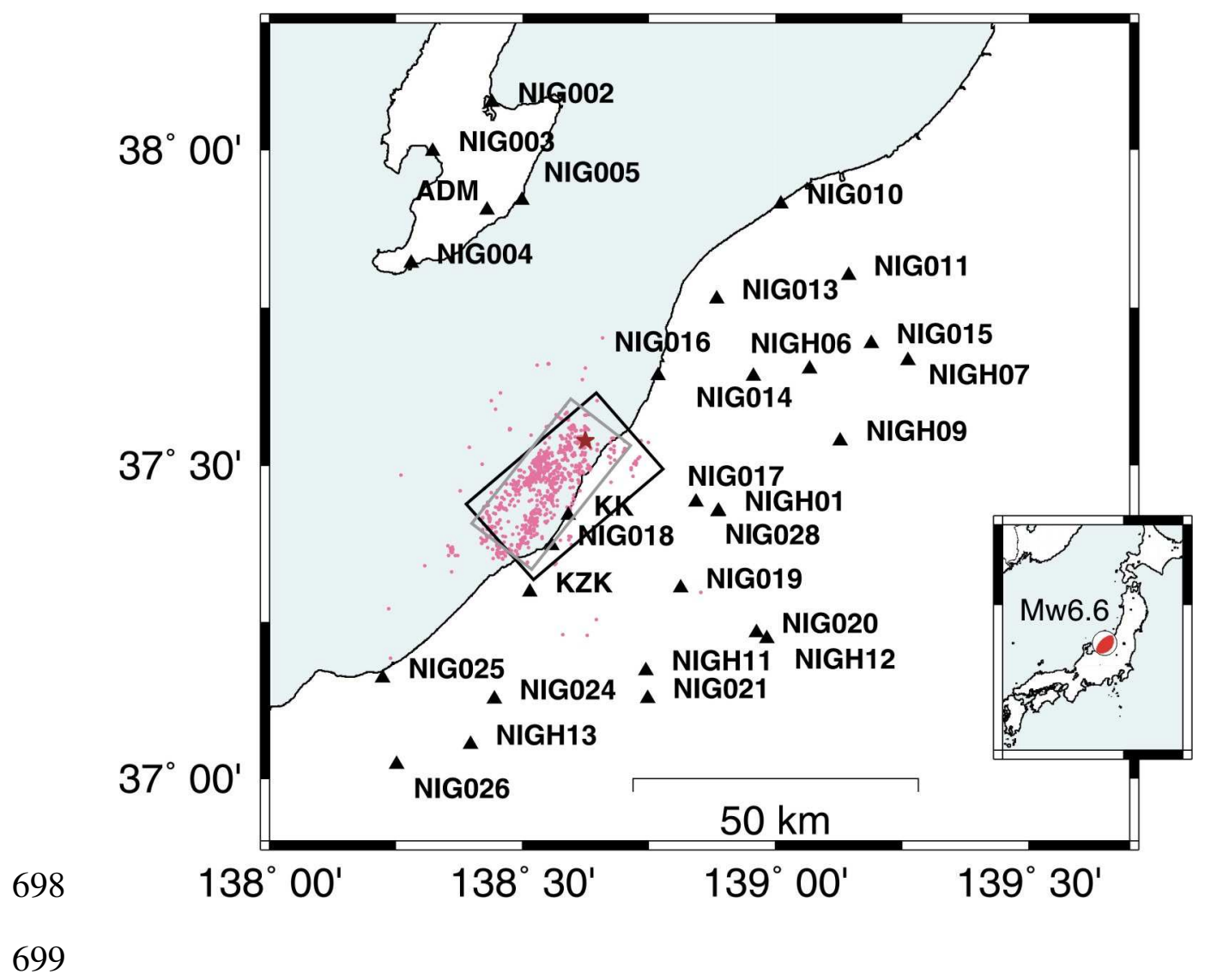


700 Figure 2:

701

702

Simulation procedure

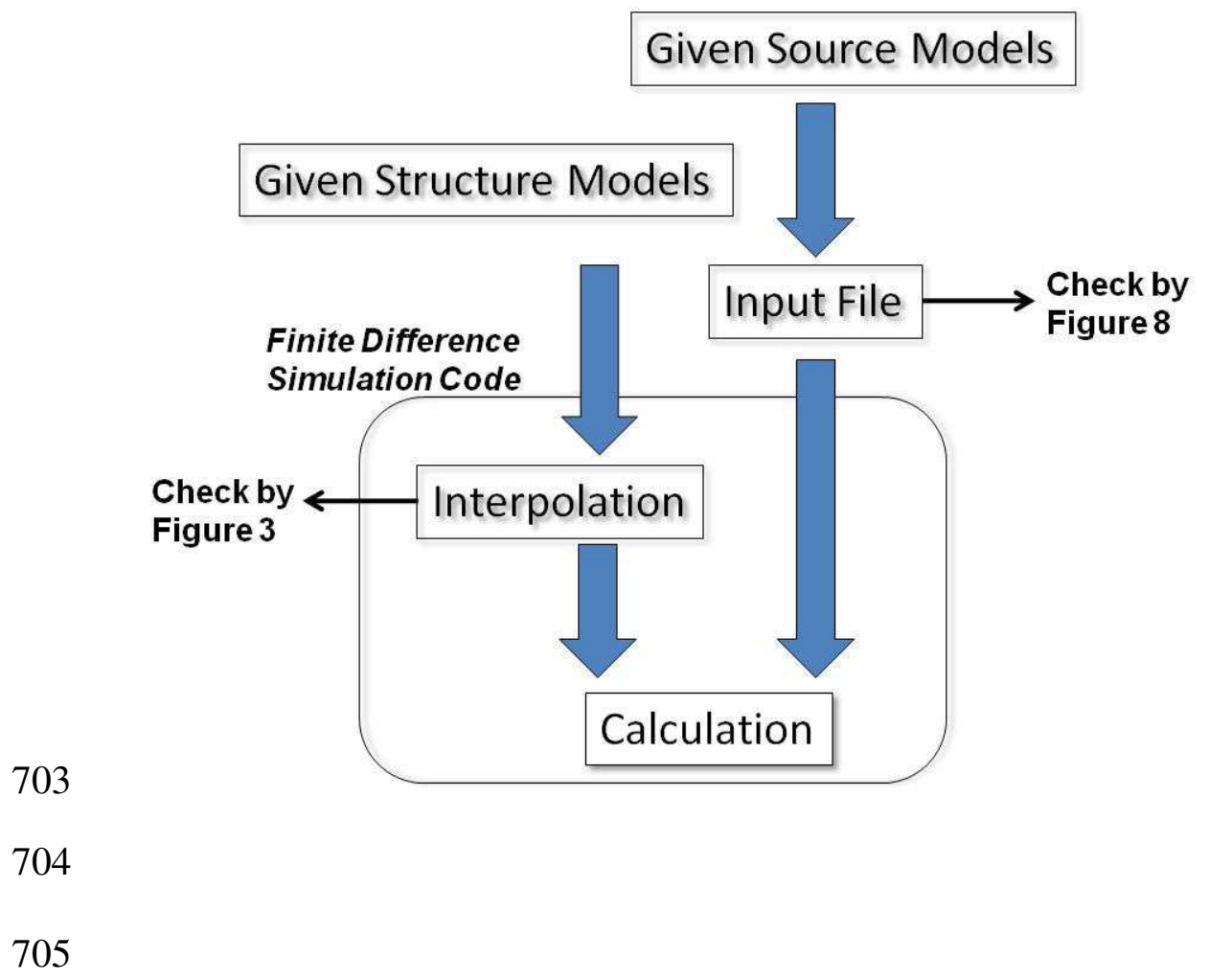


Figure 3:
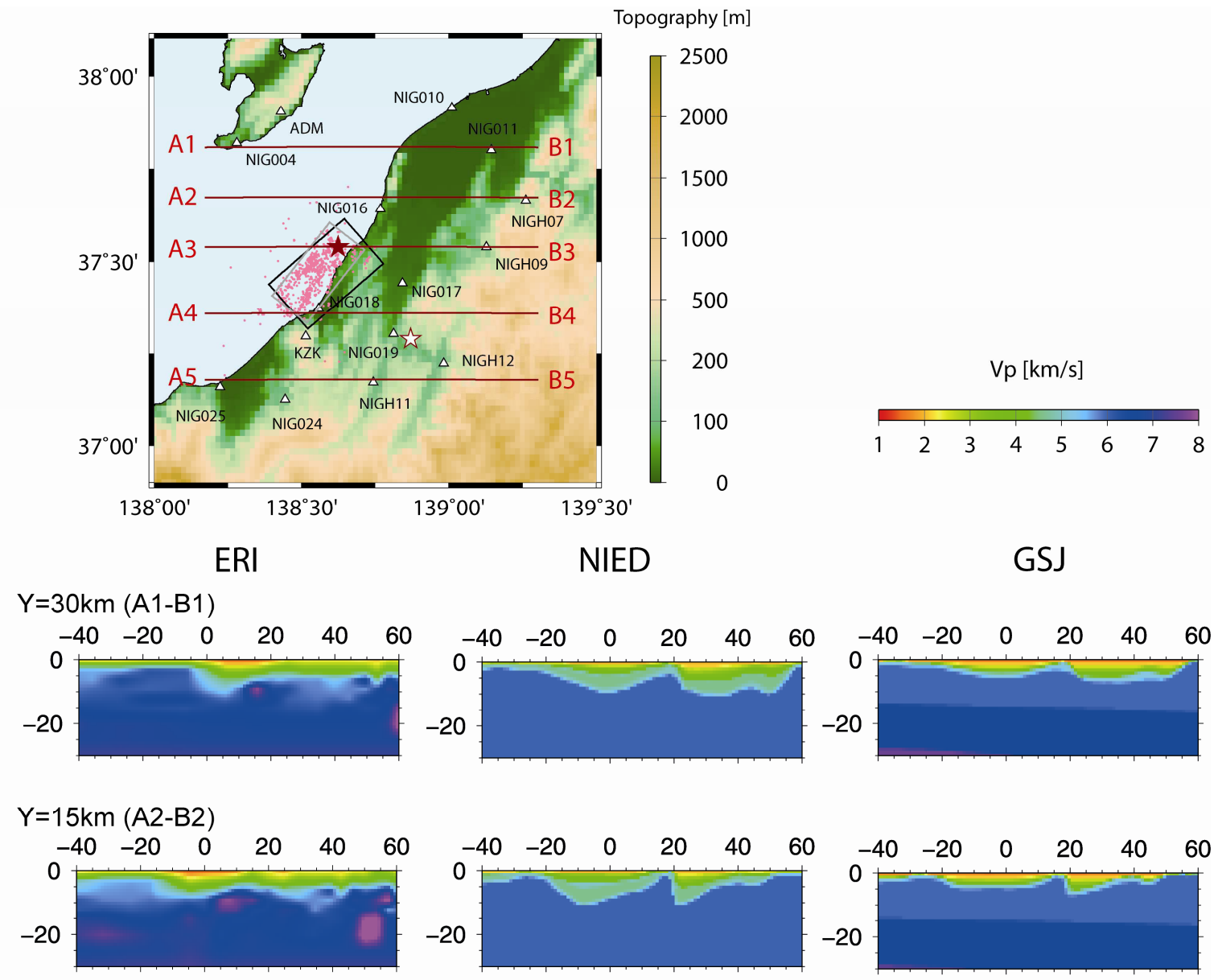

$\mathrm{Y}=0 \mathrm{~km}(\mathrm{A3}-\mathrm{B} 3)$
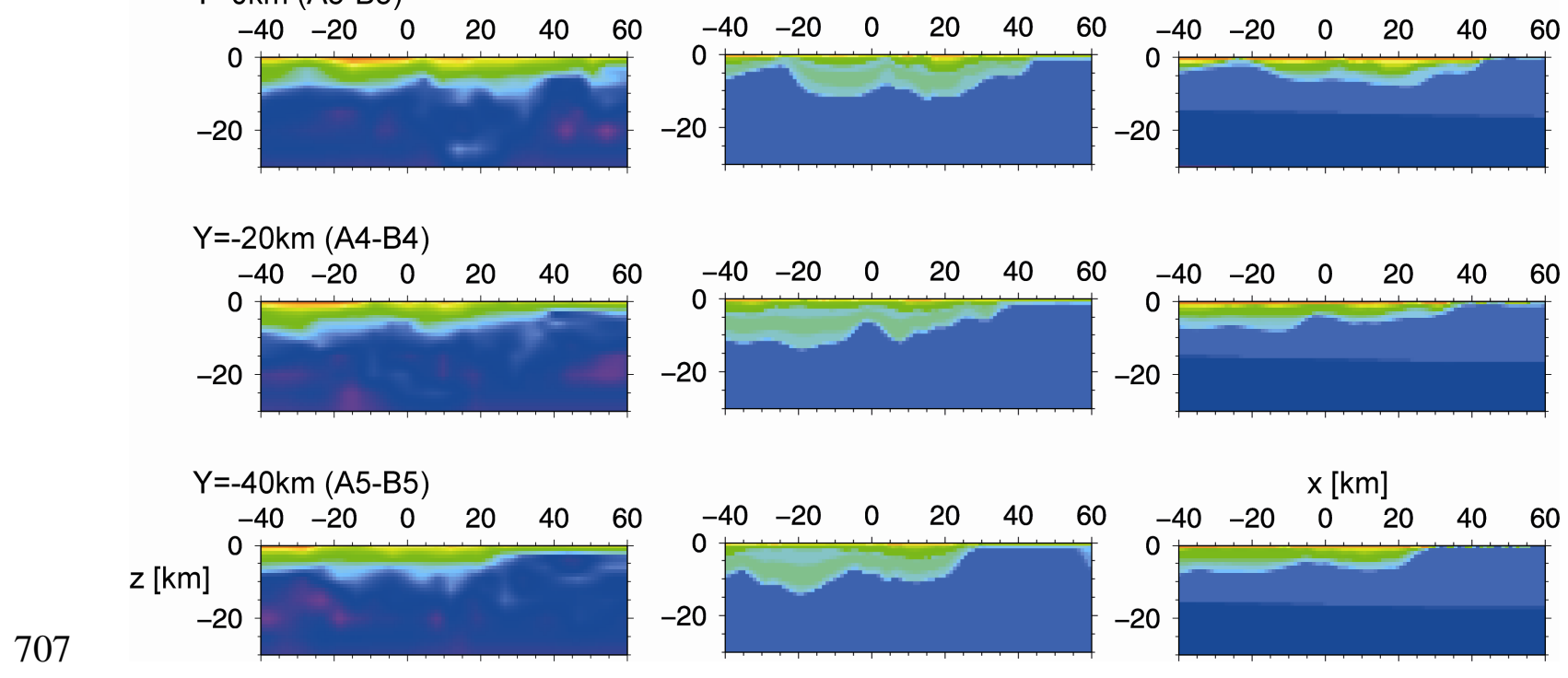
Figure 4 : (revised)

710

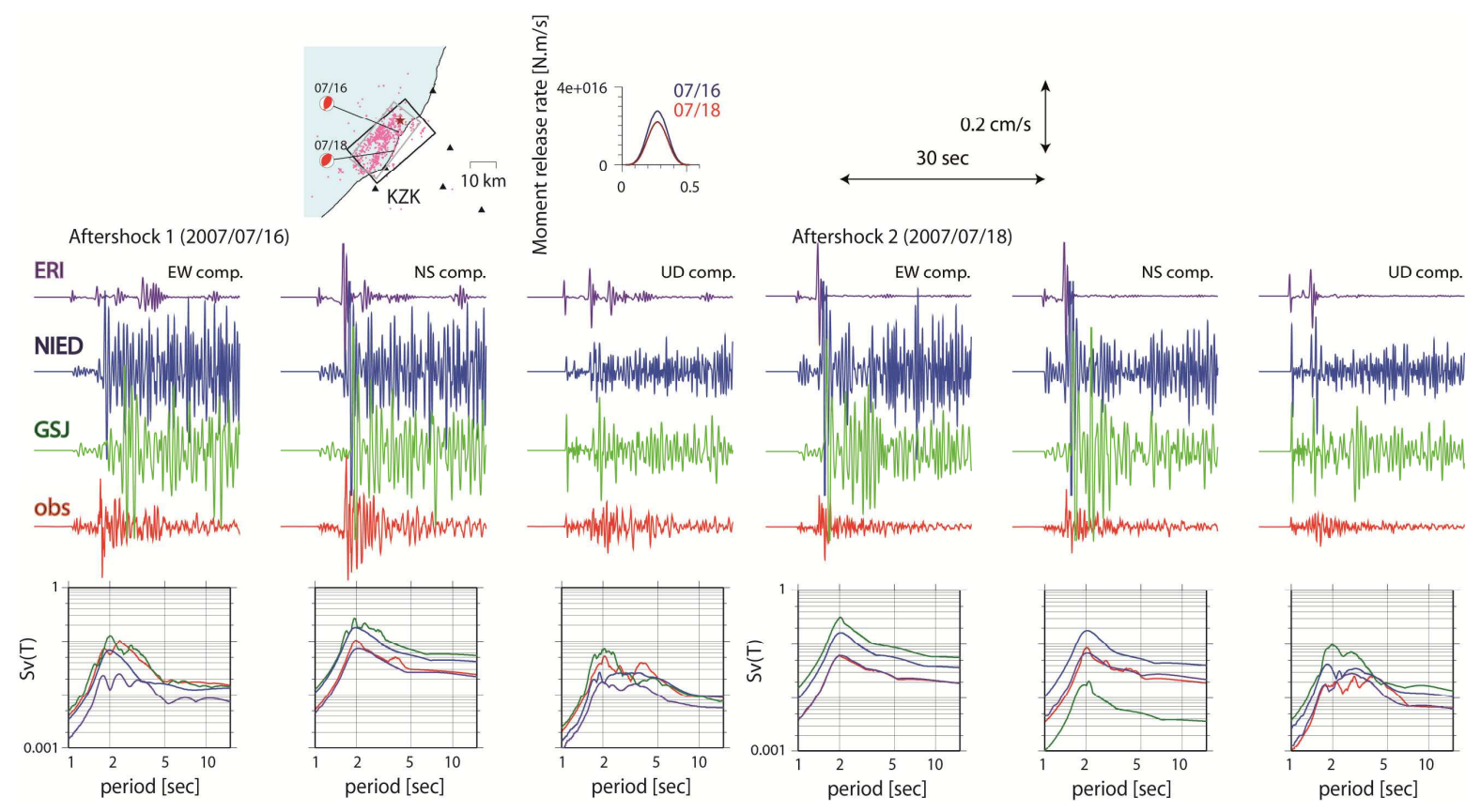

711

712 

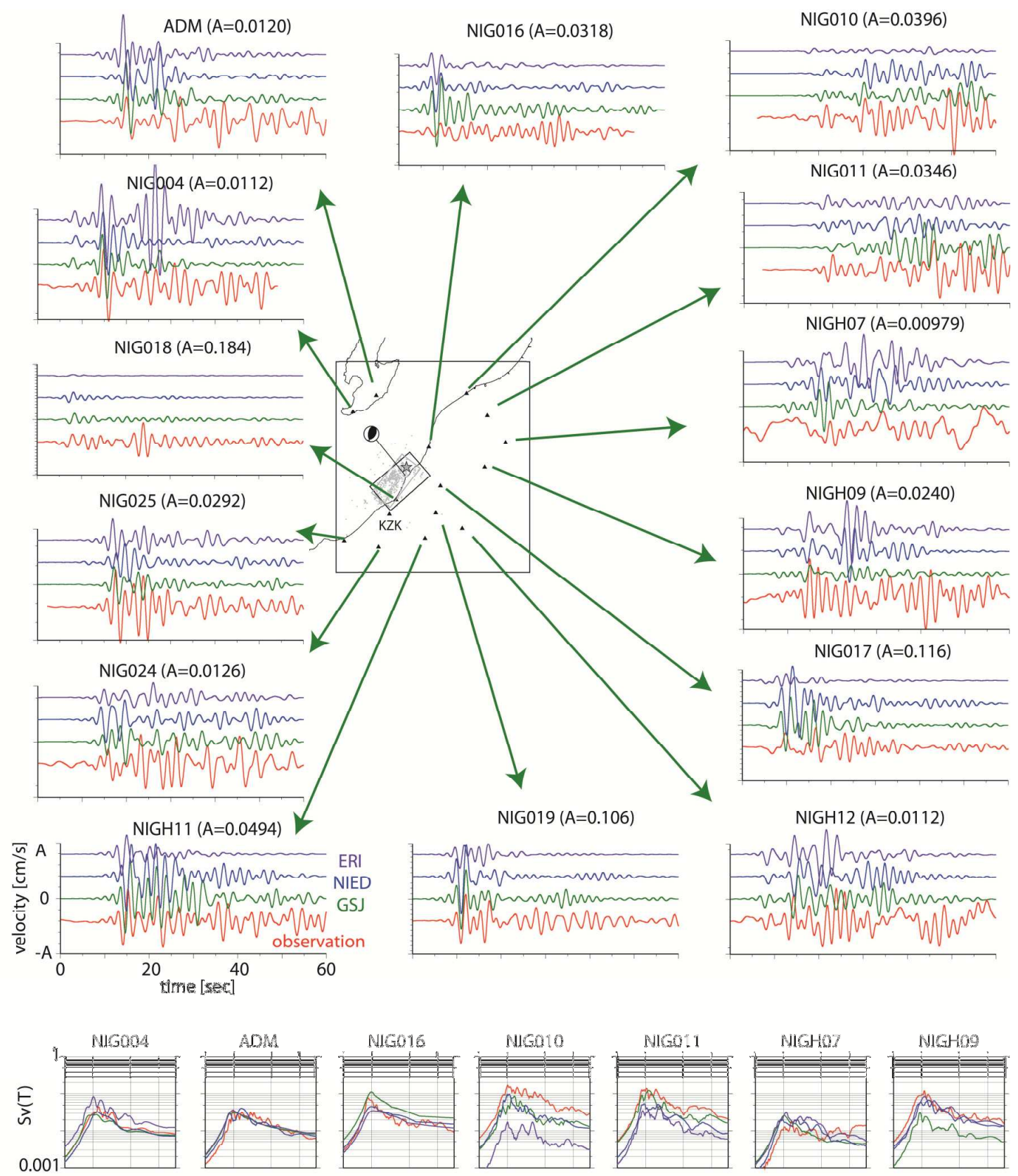

MfHog
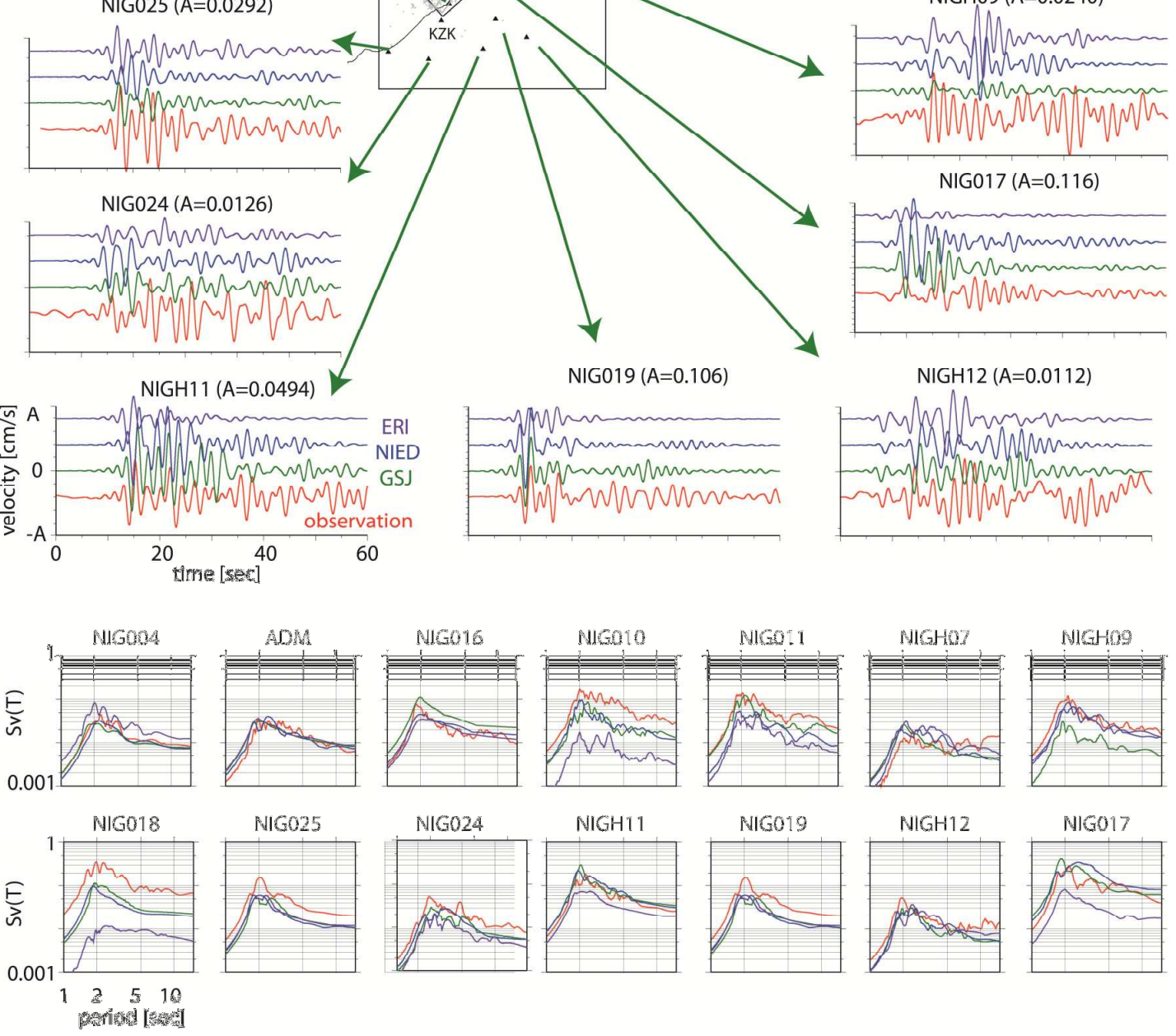


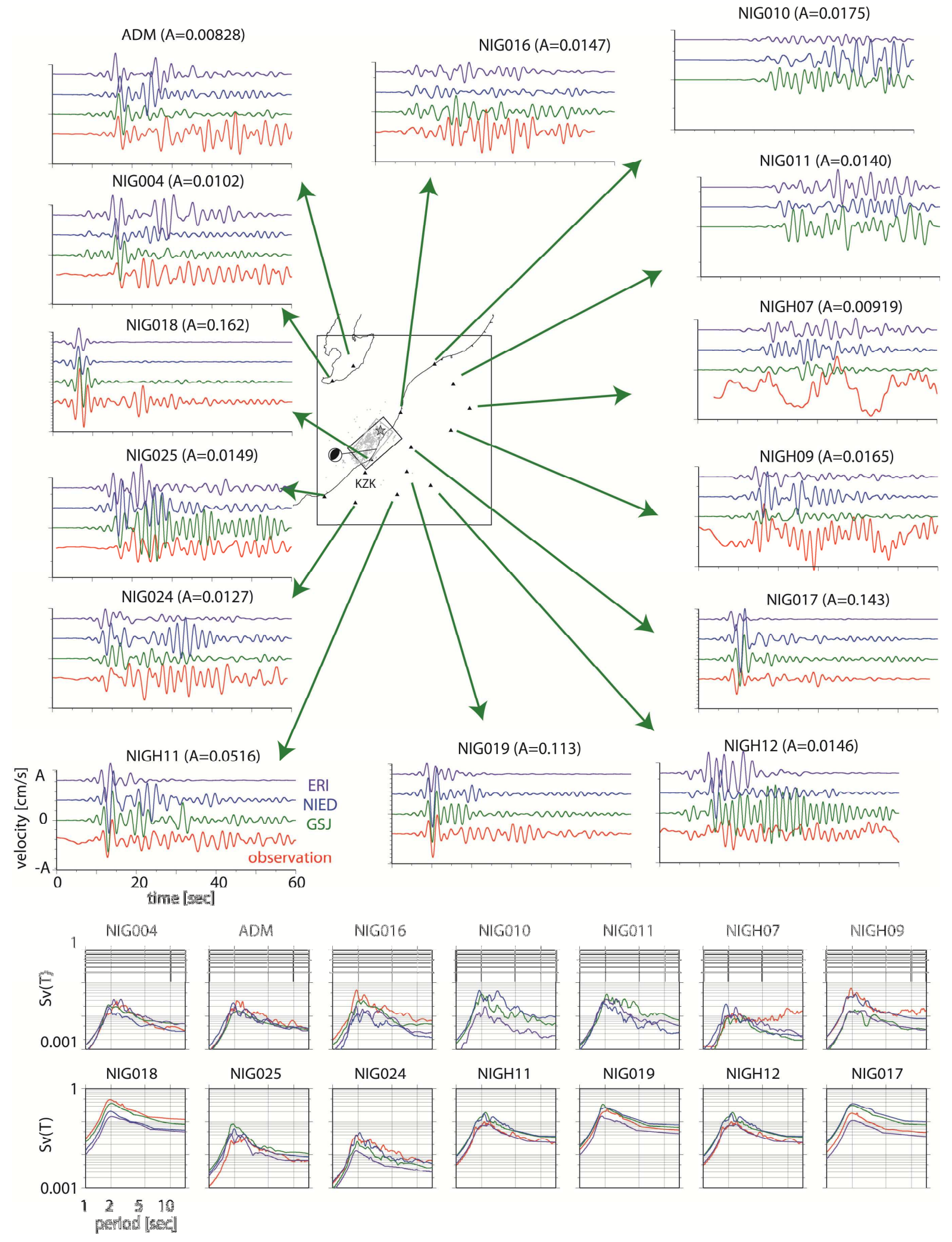


719 Figure 7:

Aoi et al. Model

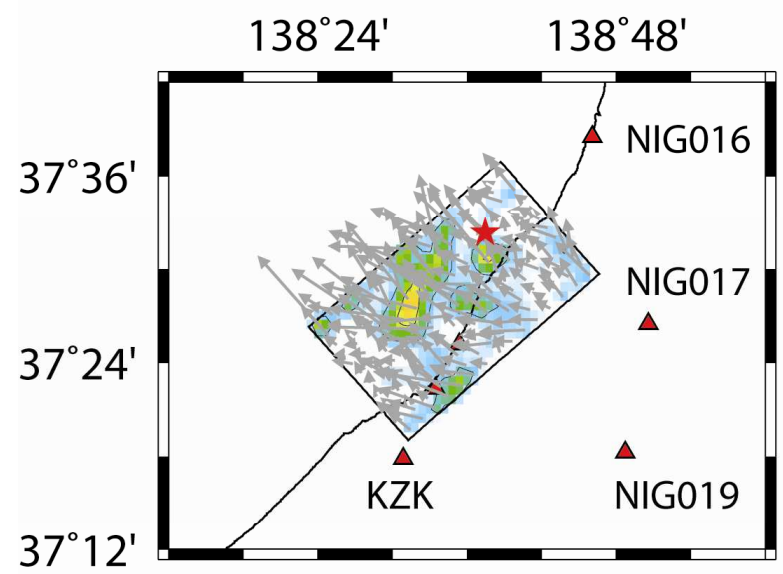

Hikima \& Koketsu Model

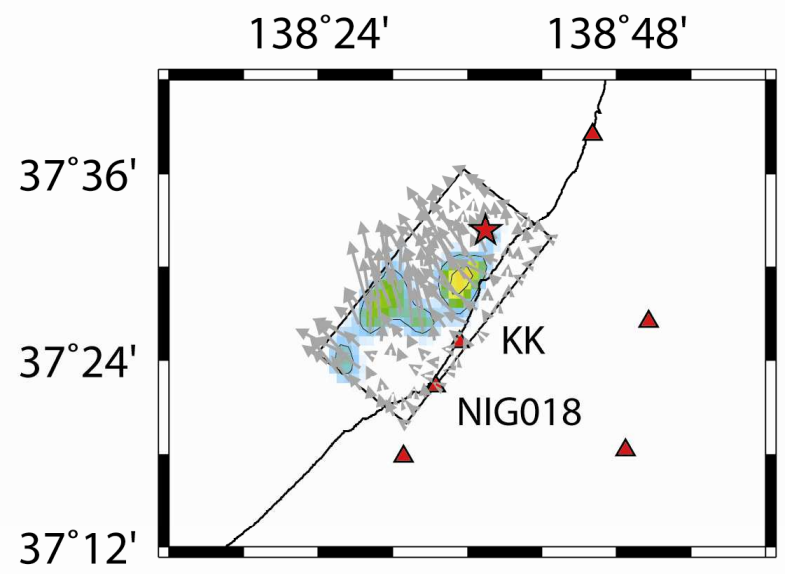

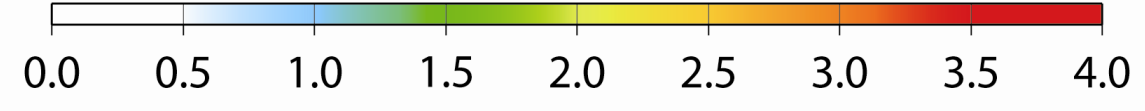

Fault slip [m] 
722 Figure 8 :

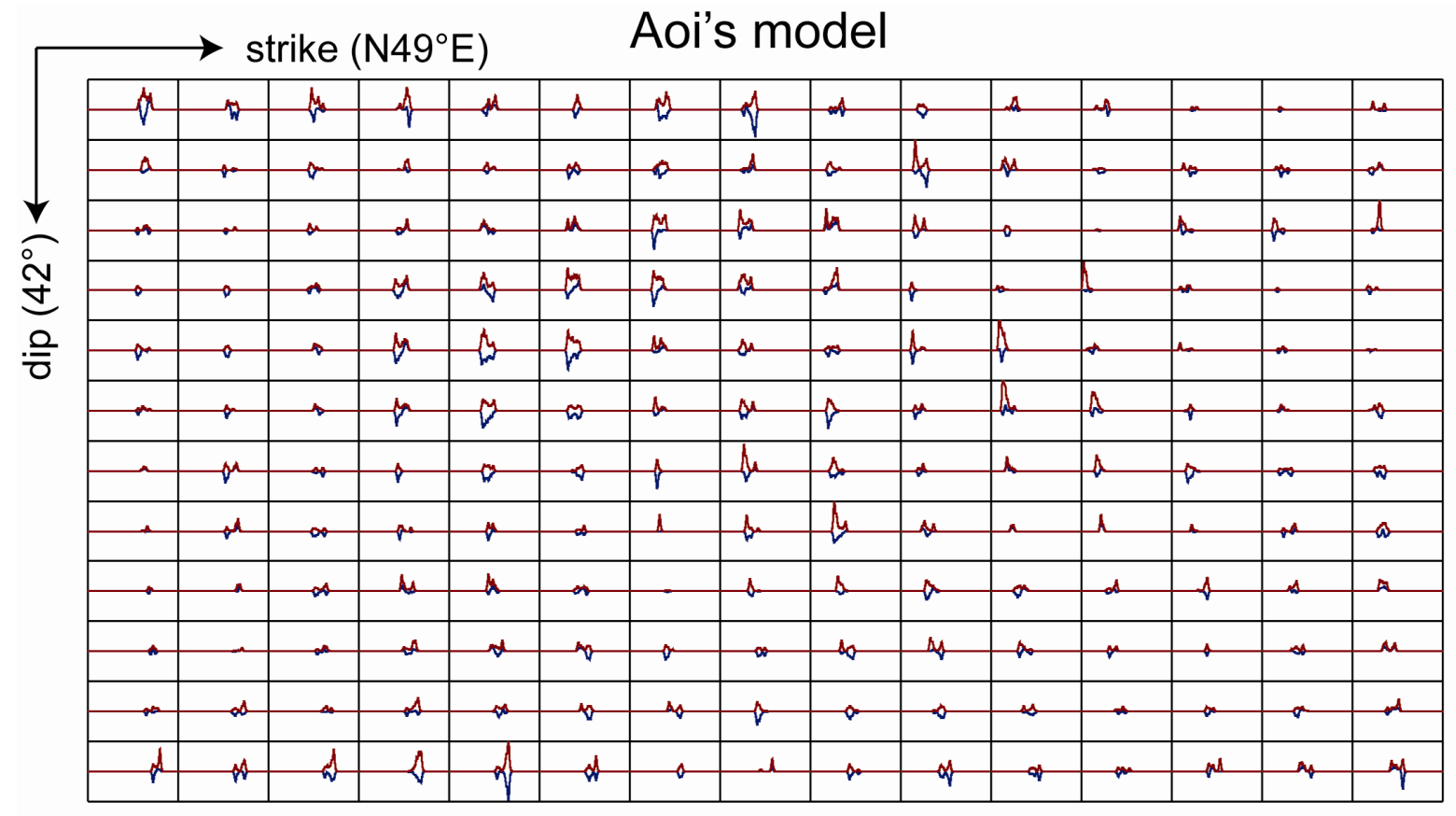

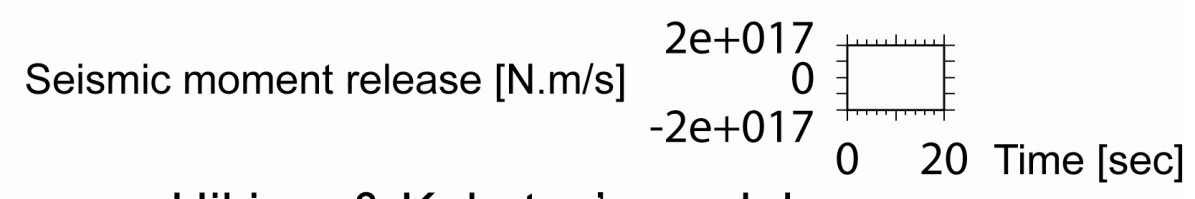

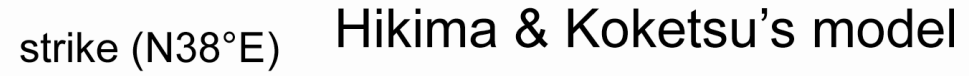

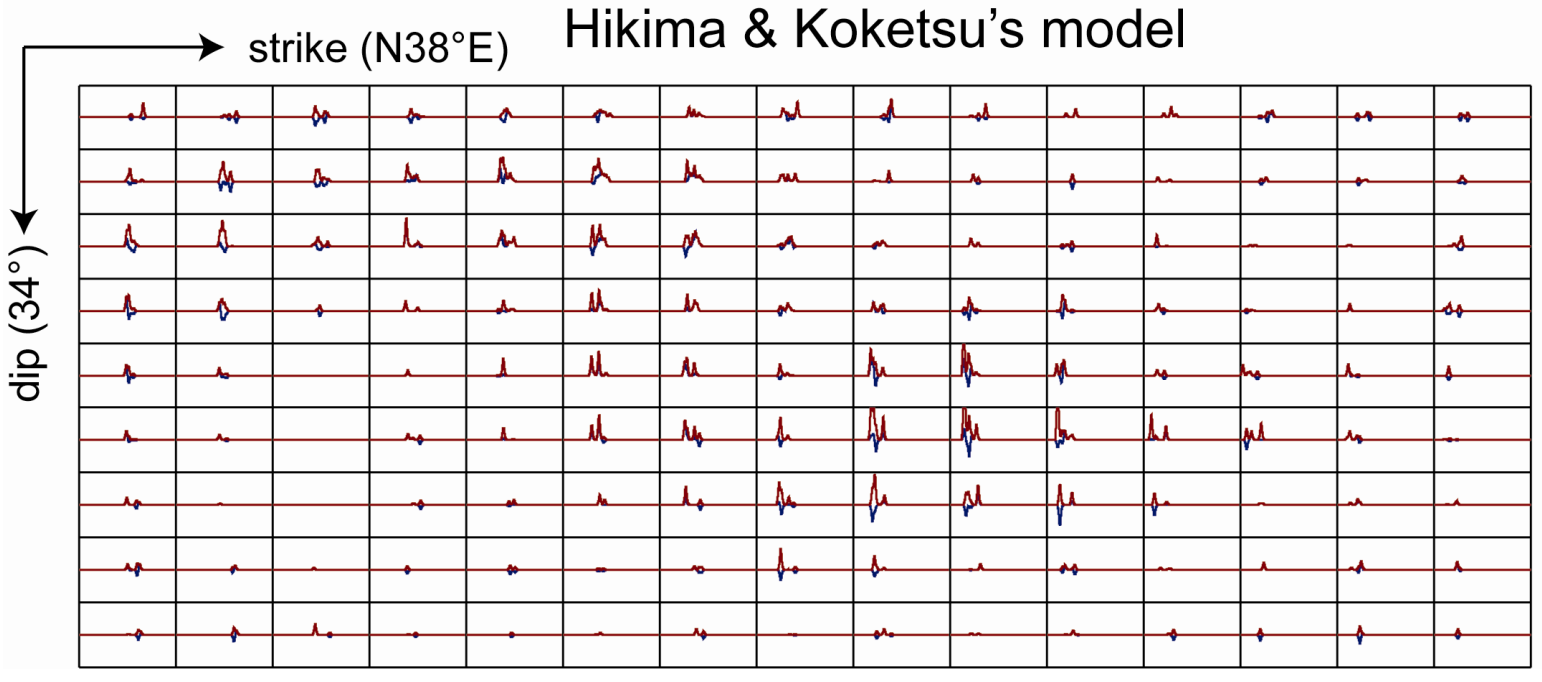


726 Figure 9:

NIG004

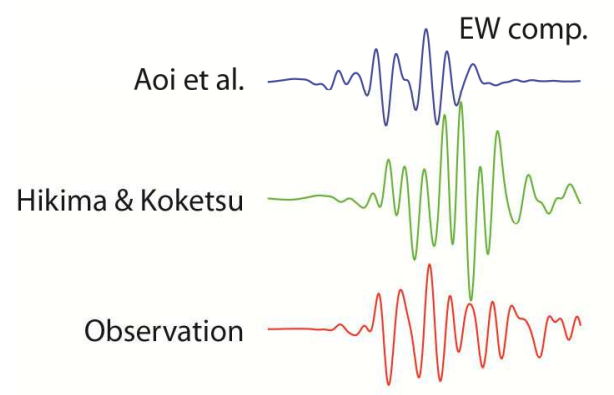

NIG016
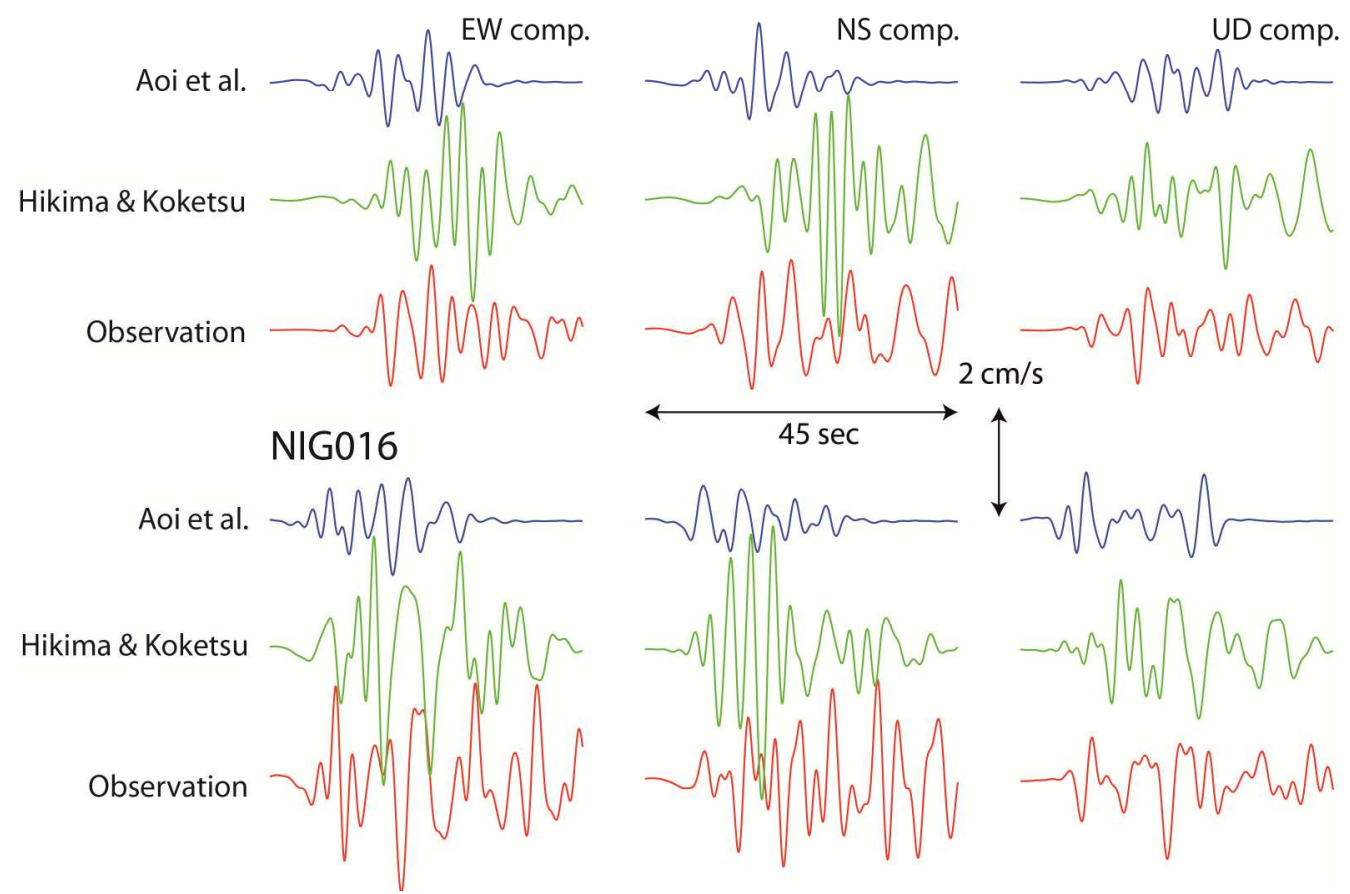

727 
Figure 10 :
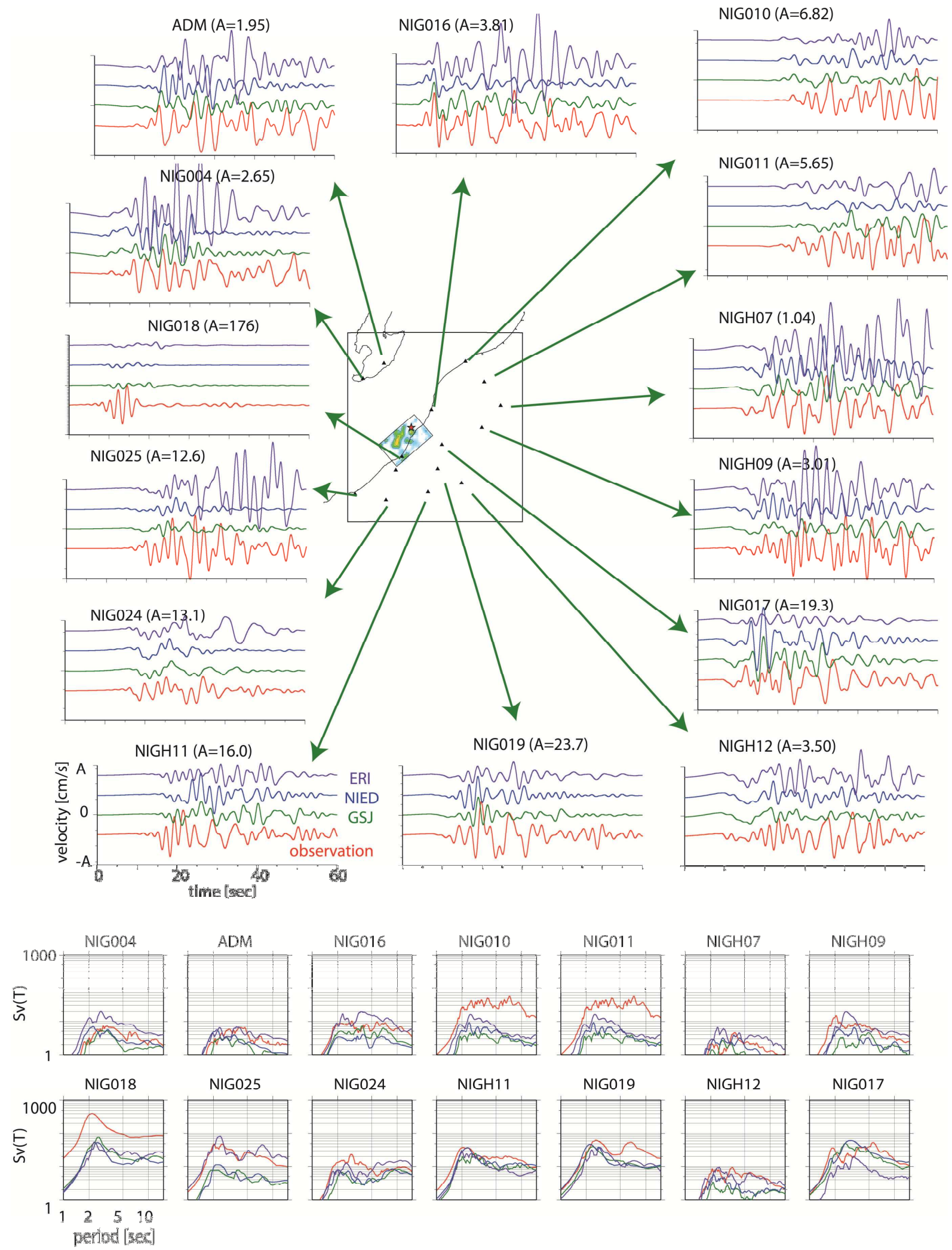


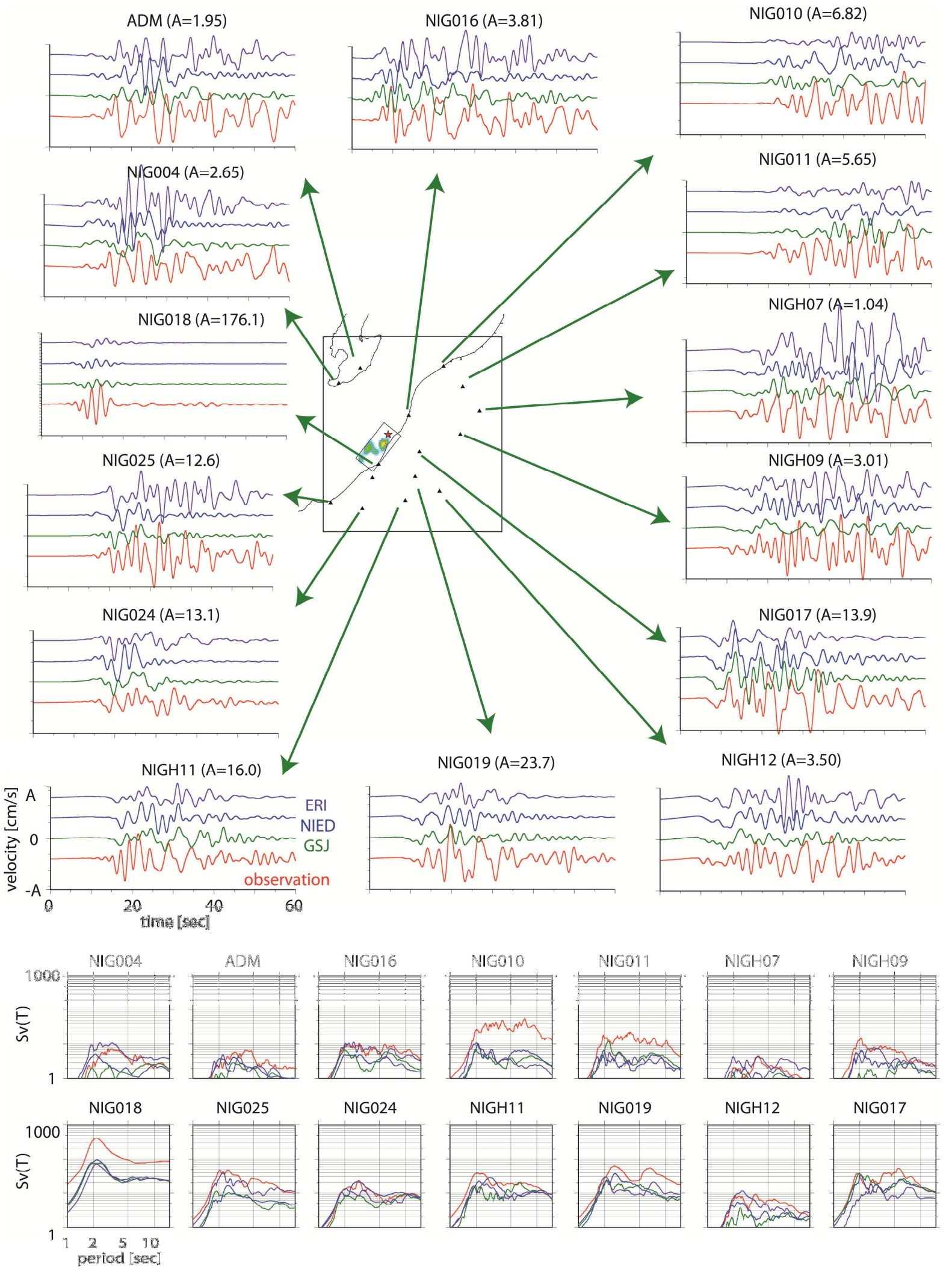


Figure 12 : (revised)

PGVx

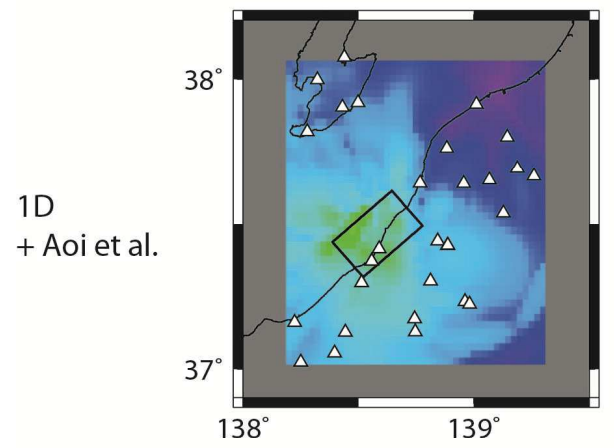

ERI

+ Aoi et al.

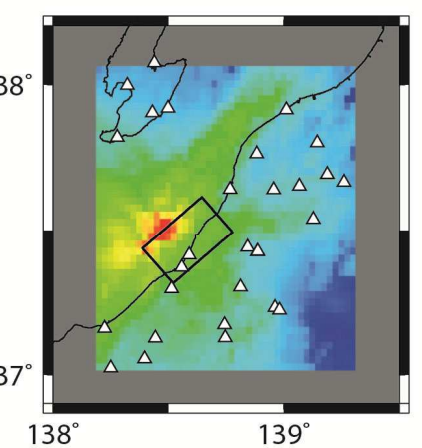

NIED

+ Aoi et al.

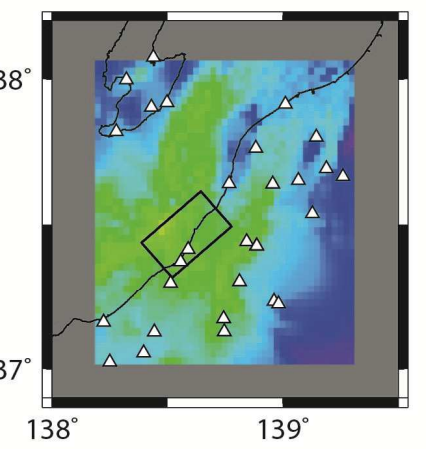

GSJ

+ Aoi et al.

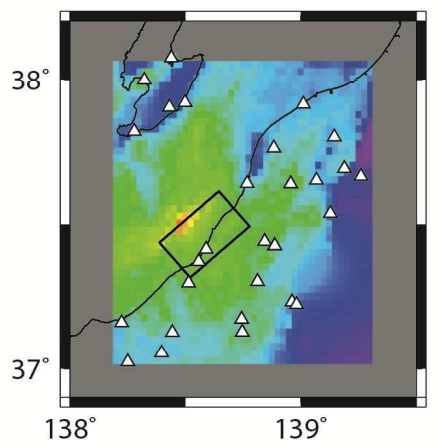

PGVy
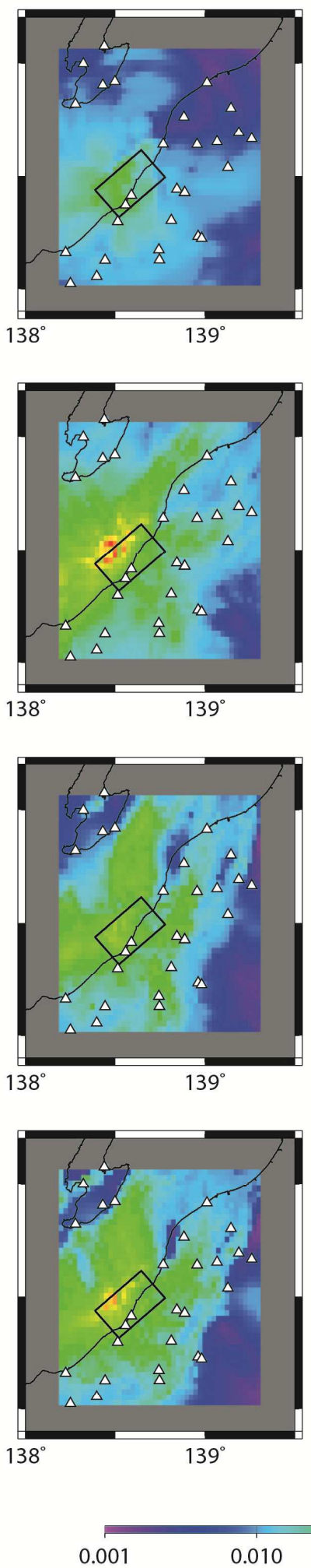

PGVz
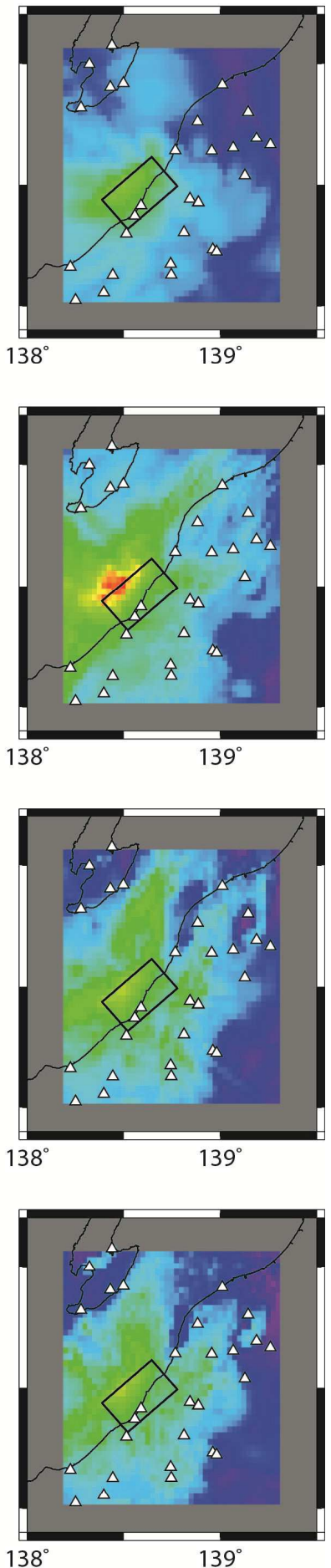

0.100 1.000 Ground velocity $\mathrm{m} / \mathrm{s}$ 
Figure 13:
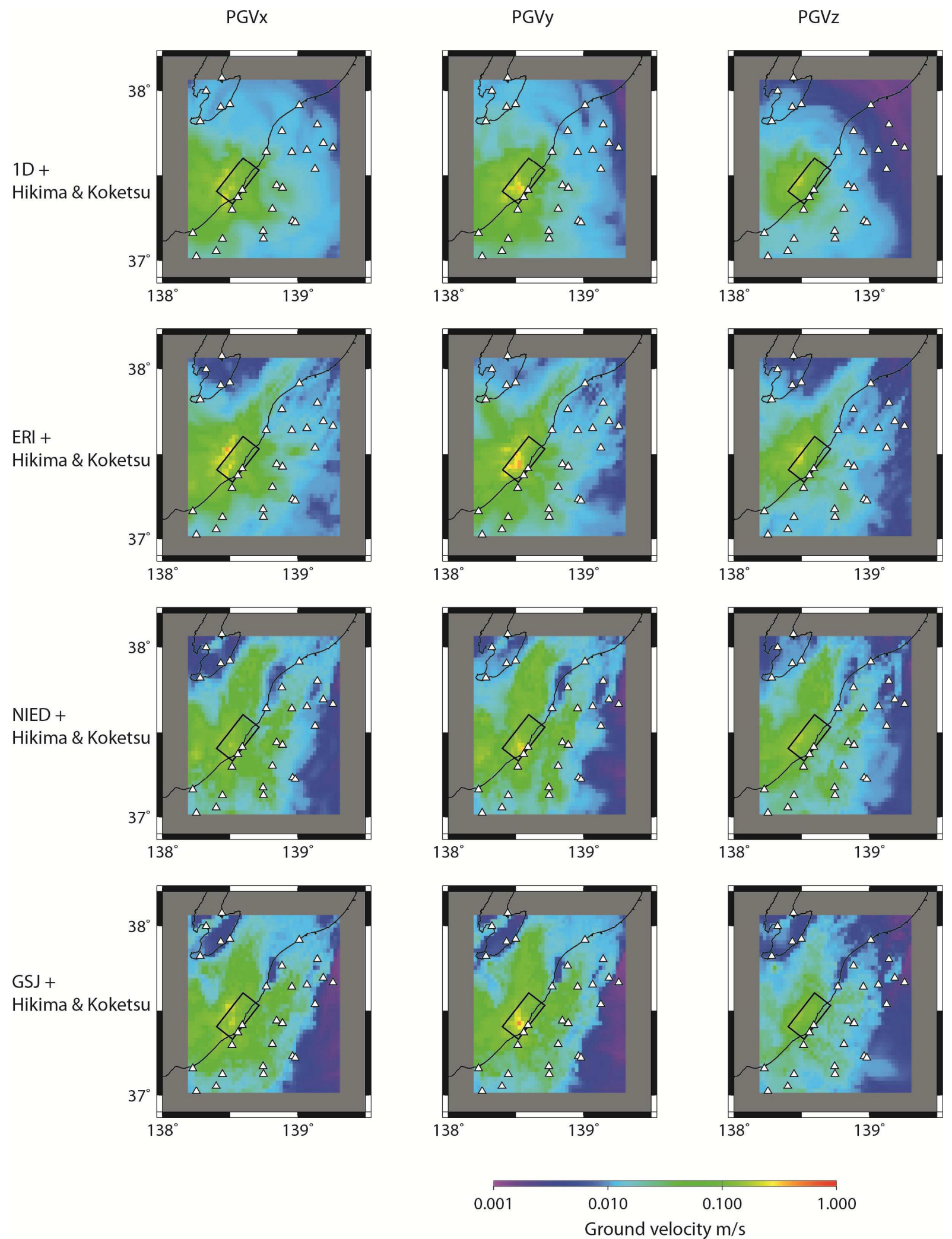
740 Figure 14 :

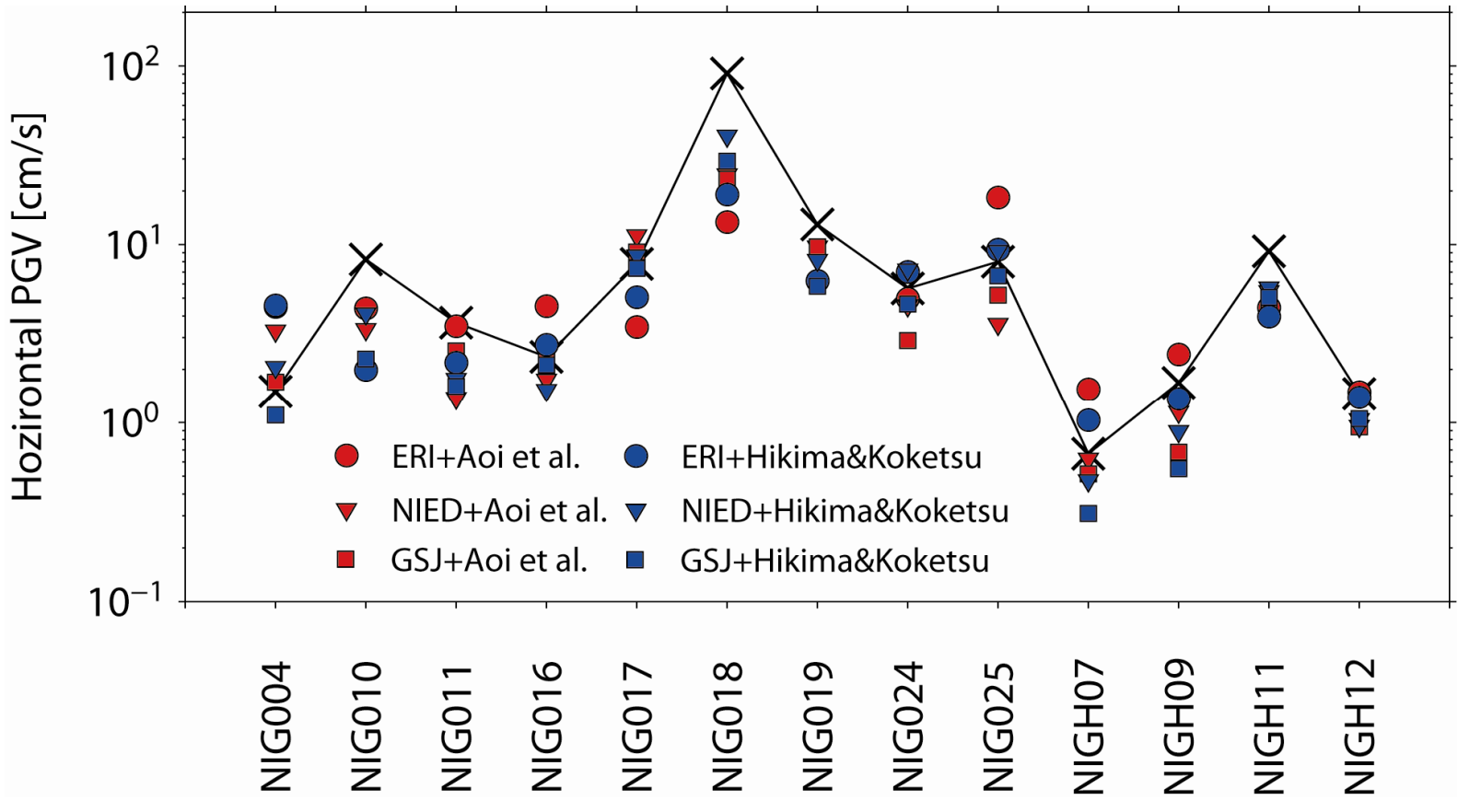

742 
744 Figure A1 :
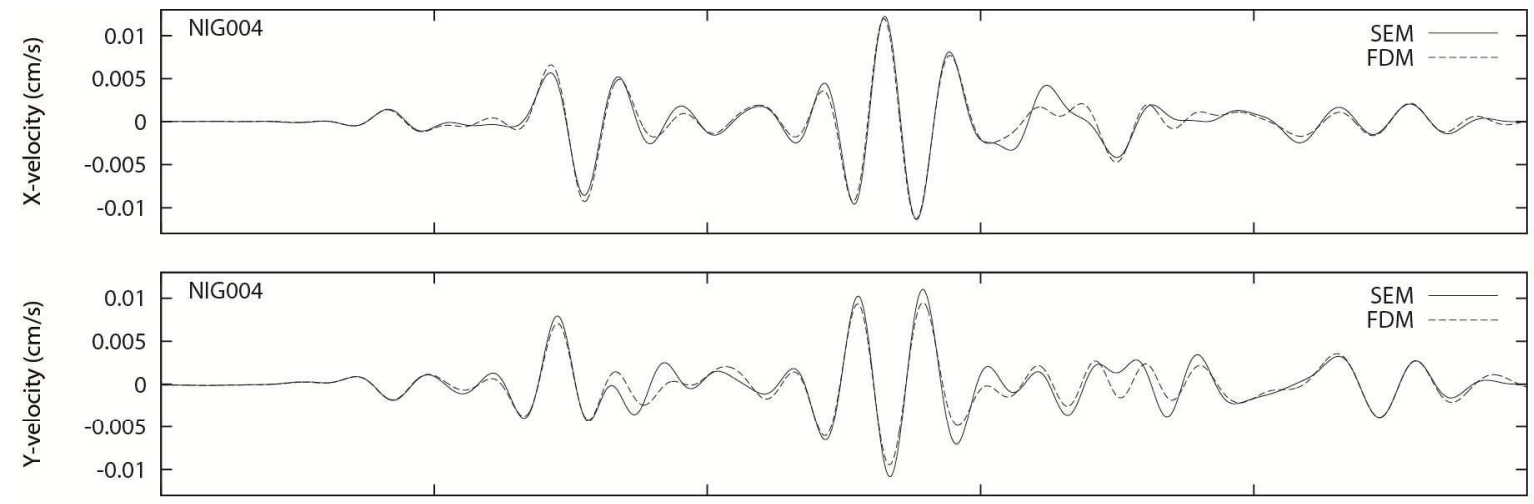

745

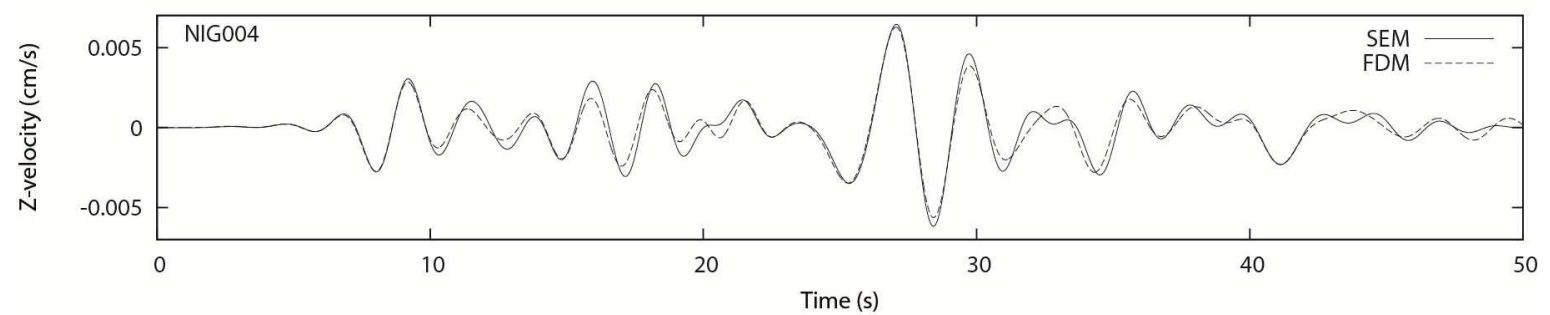

746 
748 Figure A2 :
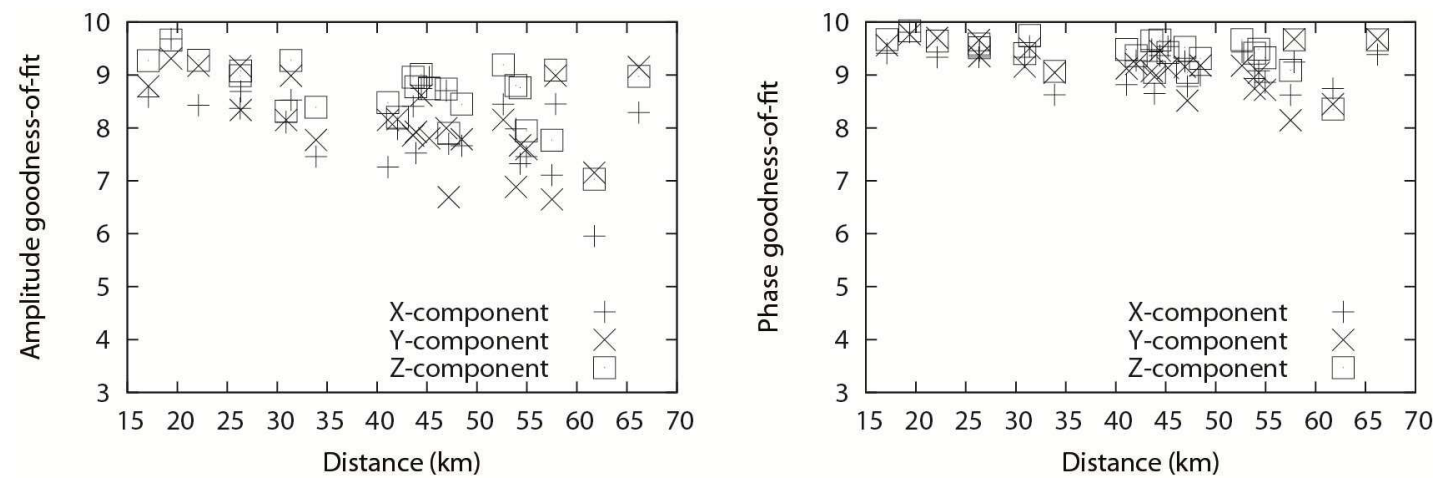

750 